\title{
Structure and surface properties of eddies in the southeast Pacific Ocean
}

\author{
James Holte, ${ }^{1}$ Fiamma Straneo, ${ }_{1}^{1}$ Carlos Moffat, ${ }^{2}$ Robert Weller, ${ }^{1}$ and J. Thomas Farrar ${ }^{1}$ \\ Received 4 January 2013; revised 22 March 2013; accepted 23 March 2013; published 7 May 2013.
}

[1] A number of studies have posited that coastally generated eddies could cool the southeast Pacific Ocean (SEP) by advecting cool, upwelled waters offshore. We examine this mechanism by characterizing the upper-ocean properties of mesoscale eddies in the SEP with a variety of observations and by estimating the surface-layer eddy heat flux divergence with satellite data. Cyclonic and anticyclonic eddies observed during two cruises featured deep positive salinity anomalies along the $26.5 \mathrm{~kg} \mathrm{~m}^{-3}$ isopycnal, indicating that the eddies had likely trapped and transported coastal waters offshore. The cyclonic eddies observed during the cruises were characterized by shoaling isopycnals in the upper $200 \mathrm{~m}$ and cool near-surface temperature anomalies, whereas the upper-ocean structure of anticyclonic eddies was more variable. Using a variety of large-scale observations, including Argo float profiles, drifter records, and satellite sea surface temperature fields, we show that, relative to mean conditions, cyclonic eddies are associated with cooler surface temperatures and that anticyclonic eddies are associated with warmer surface temperatures. Within each data set, the mean eddy surface temperature anomalies are small and of approximately equal magnitude but opposite sign. Eddy statistics drawn from satellite altimetry data reveal that cyclonic and anticyclonic eddies occur with similar frequency and have similar average radii in the SEP. A satellite-based estimate of the surface-layer eddy heat flux divergence, while large in coastal regions, is small when averaged over the SEP, suggesting that eddies do not substantially contribute to cooling the surface layer of the SEP.

Citation: Holte, J., F. Straneo, C. Moffat, R. Weller, and J. T. Farrar (2013), Structure and surface properties of eddies in the southeast Pacific Ocean, J. Geophys. Res. Oceans, 118, 2295-2309, doi:10.1002/jgrc.20175.

\section{Introduction}

[2] The southeast Pacific Ocean (SEP) features the world's largest and most persistent subtropical stratocumulus cloud deck, extending from the equator to central Chile and approximately $1500 \mathrm{~km}$ offshore. The clouds reflect incoming solar radiation and contribute significantly to Earth's radiation balance and climate [Hartmann et al., 1992; Klein and Hartmann, 1993]. They also reduce the amount of solar radiation reaching the sea surface, helping to maintain the relatively cool sea surface temperatures (SSTs) of the SEP [Ma et al., 1996; Gordon et al., 2000]. The cool SSTs, in turn, help maintain the clouds by strengthening the atmospheric inversion [Norris and Leovy, 1994].

[3] The coupling between the ocean and atmosphere in this region is not well understood, and many coupled Global

\footnotetext{
${ }^{1}$ Woods Hole Oceanographic Institution, Woods Hole, Massachusetts, USA.

${ }^{2}$ Departamento de Oceanografía y Programa COPAS Sur-Austral, Universidad de Concepción, Concepción Chile.

Corresponding author: J. Holte, Woods Hole Oceanographic Institution, 266 Woods Hole Rd MS \#21, Woods Hole, MA 02543, USA. (jholte@whoi.edu)

(C)2013. American Geophysical Union. All Rights Reserved. 2169-9275/13/10.1002/jgrc. 20175
}

Climate Models (GCMs) do not correctly reproduce the extensive stratus clouds or cool SSTs of the SEP [Mechoso et al., 1995; Boville and Gent, 1998; Ma et al., 1996; Lin, 2007; de Szoeke and Xie, 2008; Lauer et al., 2010]. All 19 coupled GCMs used in the Intergovernmental Panel on Climate Change (IPCC) Fourth Assessment Report had warm SST biases in the SEP [Zheng et al., 2011]. These biases, which limit the models' abilities to simulate Earth's climate, are likely due in part to poor model representation of both upper-ocean heat transport and the surface heat budget [Large and Danabasoglu, 2006; de Szoeke et al., 2010; Zheng et al., 2010; Colas et al., 2011].

[4] Observation-based heat budgets in the SEP have shown that the upper ocean requires an input of fresh, cold water to balance evaporation and a net surface heat flux into the ocean of approximately $44 \mathrm{~W} \mathrm{~m}^{-2}$ [Colbo and Weller, 2007]. Examining the upper $250 \mathrm{~m}$ of the ocean, Colbo and Weller [2007] concluded that the mean equatorward gyre circulation compensated for nearly half of the heat imbalance, whereas Ekman transport and pumping made a negligible contribution. Vertical mixing driven, for example, by nearinertial oscillations could also cool the mixed layer, but was justifiably assumed to be small at $250 \mathrm{~m}$, a depth more than $100 \mathrm{~m}$ below the base of the mixed layer. Colbo and Weller [2007] proposed that the horizontal eddy heat flux 
divergence accounted for the remainder of the heat budget, although they could not directly estimate it.

[5] In general, eddy heat flux derives from correlations between velocity $(v)$ and temperature $(T)$ fluctuations about some suitably defined background state (e.g., the time mean), commonly represented as $\overline{v^{\prime} T^{\prime}}$. This quantity is difficult to estimate with available observations; estimates from satellite data are confined to the surface layer [Stammer, 1998], and depth estimates require extensive subsurface velocity observations [Wunsch, 1999]. The advection fields associated with eddies can transport and diffuse heat through complex mixing and stirring patterns. One component of the eddy flux involves water trapped within the eddy cores [e.g., Sparrow et al., 2002; Lehahn et al., 2011; and Early et al., 2011]. If an eddy's rotational velocity exceeds its propagation speed, water can be trapped and transported within the eddy; as the eddy decays, this water is dispersed and can contribute significantly to the total eddy heat flux [Treguier et al., 2003; Colas et al., 2011].

[6] In the SEP, coastal upwelling, driven by northward winds along South America, causes isopycnals to tilt up toward the coast, bringing cooler sub-surface waters closer to the surface [Blanco et al., 2001; Schneider et al., 2003]. Eddies in the SEP form near Chile and Peru's coasts, likely due to baroclinic instability of the coastal currents [Leth and Shaffer, 2001; Leth and Middleton, 2004], and propagate westward [Chaigneau and Pizarro, 2005a; Johnson and McTaggart, 2010; Chelton et al., 2011; Chaigneau et al., 2011]. Cyclonic eddies tend to have surfaceintensified velocity signals, likely due to their formation in the Peru-Chile Current, whereas anticyclonic eddies tend to have subsurface velocity maxima related to the PeruChile Undercurrent (PCU) [Johnson and McTaggart, 2010; Chaigneau et al., 2011; Colas et al., 2011]. Both cyclonic and anticyclonic eddies generated near the coast of Chile could cool the SEP through horizontal mixing of cool, upwelled coastal waters offshore as well as through the direct transport and eventual dispersion of cool, upwelled water trapped within the eddies.

[7] While Colbo and Weller [2007] invoked the eddy heat flux divergence to close their heat balance, no observational studies have confirmed their estimate and modeling studies have produced conflicting results on the importance of eddy heat flux. For example, using GCM simulations, Zheng et al. [2010] found that the net incoming heat flux imbalance of $18 \mathrm{~W} \mathrm{~m}^{-2}$ was nearly fully balanced by the gyre circulation of upwelled cold water from the coast; the eddy heat flux divergence term was not spatially coherent, and therefore did not contribute to maintaining the cool SSTs. A similar conclusion was reached by Toniazzo et al. [2010] using a high-resolution model for an analysis of the oceanic heat advection in the upper $500 \mathrm{~m}$ of the SEP. Colas et al. [2011] used a regional ocean model to show that, within $700 \mathrm{~km}$ of the coast off of Peru, both the mean heat transport and the eddy heat flux were essential to the SEP's overall heat balance; off of Chile the eddy contribution was much smaller. Thus the role of eddies in closing the SEP's heat budget is still unclear, partially due to our incomplete knowledge about the structure and properties of eddies in the SEP.

[8] In this study, a variety of observations were used to examine the upper-ocean structure and surface temperature signals of eddies in the SEP, as well as to estimate the eddy heat flux divergence. The available observations were inadequate for fully diagnosing the eddy heat flux divergence, but we used available observations to characterize the vertical structure and core properties of the eddies and to describe aspects of their heat flux at the surface. We focused on a region of the SEP that extended along the coast of northern Chile from $15^{\circ} \mathrm{S}$ to $35^{\circ} \mathrm{S}$, and offshore to $100^{\circ} \mathrm{W}$. The hydrographic and velocity structures of cyclonic and anticyclonic eddies in the SEP were first characterized using data from VOCALS-REx (VAMOS Ocean Cloud Atmosphere Land Study-Regional Experiment; VAMOS stands for Variability of the American Monsoon Systems), an extensive field campaign that surveyed upper-ocean and atmospheric properties in the SEP [Wood et al., 2011]. Data from a more recent cruise in the region, referred to as Stratus 2011 throughout the paper, were also used to examine eddy structure. Together, these cruises afforded us some of the most detailed synoptic observations available of eddies in the SEP. The observations provide evidence of eddy-core trapping in both cyclonic and anticyclonic eddies, and of differing nearsurface temperature anomalies for cyclonic (cool) and anticyclonic (either cool or warm) eddies. The near-surface eddy properties suggested by the limited cruise data were generalized for the SEP using Argo float profiles, drifter records, satellite SST fields, and Chelton et al. [2011]'s (hereafter $\mathrm{CH} 2011)$ eddy census. In all of the data sets, we found that cyclonic eddies were associated with cooler surface temperatures relative to mean conditions, whereas anticyclonic eddies were associated with warmer surface temperatures. No type of eddy predominated in the SEP, as cyclonic and anticyclonic eddies occurred in similar numbers and had similar average radii in $\mathrm{CH} 2011$. A satellite-based estimate of the eddy heat flux divergence in the surface layer was small when averaged over the entire SEP.

[9] The remainder of the paper is organized as follows. Section 2 outlines the data used in the study. The eddy observations from VOCALS-REx and Stratus 2011 are described in section 3, particularly the evidence of eddy trapping. Section 4 describes the eddy property anomalies. Section 5 considers the relationship between eddy sea level anomaly (SLA) and upper-ocean temperature for a variety of data sources. The surface-layer eddy heat flux divergence is estimated in section 6 . The results are summarized and discussed in section 7 .

\section{Data}

[10] A variety of data sources were utilized in this analysis. Synoptic data from VOCALS-REx, as well as the more recent Stratus 2011 cruise, were used to characterize eddy structure in the SEP. Additionally, Argo float, drifter, and satellite data were used to expand the spatial and temporal reach of the analysis. In general, the data used in this study were collected between October 2000 and January 2011 and spanned a region from $15^{\circ} \mathrm{S}$ to $35^{\circ} \mathrm{S}$ and $70^{\circ} \mathrm{W}$ to $100^{\circ} \mathrm{W}$.

[11] A VOCALS-REx cruise (23 October to 30 November 2008) surveyed the SEP in early spring, just as the winter mixed layers were beginning to restratify (Figure 1). The shipboard observations used here, collected from the NOAA Ship Ronald H. Brown, were one component of the much larger VOCALS study, which sought to understand the ocean, cloud, atmosphere, and land interactions that 


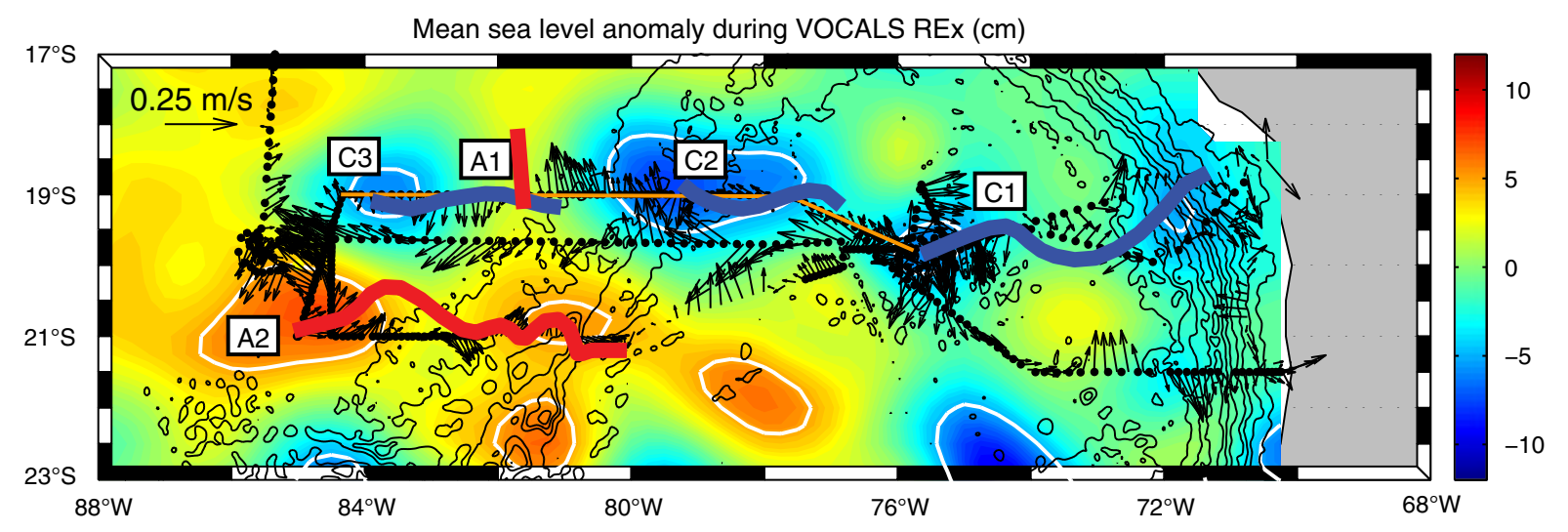

Figure 1. Locations of the 438 UCTD profiles collected during VOCALS-REx (black dots). The underway ADCP velocities (black arrows) are averaged over 50-650 m depth. The background colored contours represent the mean sea level anomaly (SLA) during the cruise; the $\pm 5 \mathrm{~cm}$ SLA contours are highlighted by white contours. The locations of three cyclonic eddies $(\mathrm{C} 1, \mathrm{C} 2$, and $\mathrm{C} 3)$ and two anticyclonic eddies (A1 and A2) are labeled. The red and blue lines represent the tracks of the eddies from the CH2011 eddy census. The bathymetry is plotted at $1000 \mathrm{~m}$ intervals (black contours). The orange line (primarily along $19^{\circ} \mathrm{S}$ ) denotes the hydrographic section plotted in Figure 4.

produce and maintain the stratus deck in the SEP [Wood et al., 2011]. The cruise sampled the coastal upwelling region, as well as the offshore region characterized by persistent stratus cloud cover. The cruise entered the SEP from the north, first servicing the WHOI Stratus mooring at $20^{\circ} \mathrm{S}$ $85^{\circ} \mathrm{W}$ [Colbo and Weller, 2007], before proceeding toward the coast along $19.5^{\circ} \mathrm{S}$ and angling northeast toward the coast at $76^{\circ} \mathrm{W}$. Leaving the coast, the cruise intensively surveyed a cyclonic eddy at $76^{\circ} \mathrm{W}$ before continuing west along $19^{\circ} \mathrm{S}$. At $84^{\circ} \mathrm{W}$, the cruise jogged south to survey an anticyclonic eddy centered at $21^{\circ} \mathrm{S} 85^{\circ} \mathrm{W}$. The cruise returned to the coast along $21^{\circ} \mathrm{S}$, ending at $21.5^{\circ} \mathrm{S} 70^{\circ} \mathrm{W}$.

[12] The 438 Underway Conductivity Temperature Depth (UCTD) profiles collected during the cruise were used to characterize the hydrographic structure of the eddies. The Oceanscience UCTD allowed for underway profiles to be collected at ship speeds of up to 13 knots. The UCTD profiles were spaced between 1 and $20 \mathrm{~km}$ apart and reached depths ranging from 200 to $800 \mathrm{~m}$. The average UCTD profile depth was $430 \mathrm{~m}$. An RD Instruments $75 \mathrm{kHz}$ Ocean Surveyor Acoustic Doppler Current Profiler (ADCP) provided underway current velocities at depths from 33 to 1137 $\mathrm{m}$ at $16 \mathrm{~m}$ intervals. Velocity measurements were collected over the entire cruise track and averaged at 5 min intervals. Along-track ADCP velocities can be biased near scattering layers [e.g., King et al., 2001]; in this work, we mainly considered cross-track velocities. We also used 71 UCTD profiles from the Stratus 2011 cruise, collected over 13-15 April 2011 from R/V Moana Wave; these profiles did not have corresponding ADCP data. The Stratus 2011 cruise, returning from servicing the Stratus mooring, first surveyed the periphery of a cyclonic eddy at $20.5^{\circ} \mathrm{S} 77^{\circ} \mathrm{W}$. It then surveyed an anticyclonic eddy at $19.5^{\circ} \mathrm{S} 74^{\circ} \mathrm{W}$ during the northeastward transit to Arica, Chile.

[13] In addition to the cruise data, we used in situ profiles collected by Argo floats. These observations provided numerous eddy observations from different seasons and from a larger geographical region, allowing for a statistical analysis of eddies in the SEP. The Argo floats used in this study generally sampled to a depth of $2000 \mathrm{~m}$ and measured temperature, salinity, and pressure at roughly 75 depth levels. Vertical sample spacing for most floats was less than $20 \mathrm{~m}$ to depths of $400 \mathrm{~m}$, below which the spacing increased to $50 \mathrm{~m}$. After implementing simple quality controls to eliminate bad profiles, 14,972 Argo profiles collected between June 2003 and January 2011 remained in the region spanning $15^{\circ} \mathrm{S}$ to $35^{\circ} \mathrm{S}$ and $70^{\circ} \mathrm{W}$ to $100^{\circ} \mathrm{W}$. Argo data are available online at http://www.usgodae.org/argo/argo.html. The Argo mixed-layer properties were calculated following Holte and Talley [2009]. The method works by first modeling the general shape of each profile; it approximates the seasonal thermocline and the mixed layer with best-fit lines. It then assembles a suite of possible mixed-layer depth (MLD) values by calculating standard threshold and gradient MLDs, identifying the intersection of the thermocline and mixedlayer fits, locating profile maxima or minima, and searching for intrusions at the base of the mixed layer. Finally, it looks for groupings and patterns within the possible MLDs to select the final MLD for each profile.

[14] We also used drifter positions and temperatures from the Global Lagrangian Drifter program [Niiler et al., 1995]. Drifter data are provided every $6 \mathrm{~h}$, based on interpolation from 16-20 satellite positions per day. The depth of the temperature measurement ranged from 0.3 to $0.4 \mathrm{~m}$. Our study used only nighttime drifter data, from either midnight or 06:00 A.M. local time, to avoid diurnal heating of the surface layer. Diurnal heating effects are more of a concern for the drifter data than for the Argo data, because the drifters have a much shallower measurement depth. Even with this restriction, we employed 176,542 drifter position/temperature observations collected between October 2000 and January 2011 in the region spanning $15^{\circ} \mathrm{S}$ to $35^{\circ} \mathrm{S}$ and $70^{\circ} \mathrm{W}$ to $100^{\circ} \mathrm{W}$. Drifter data are available online at http://www.aoml.noaa.gov/envids/gld/.

[15] We utilized a number of satellite products in this study. Merged "Reference" SLA fields from Archiving, Validation, and Interpretation of Satellite Oceanographic data (AVISO) were interpolated to the location and time of 
(a)

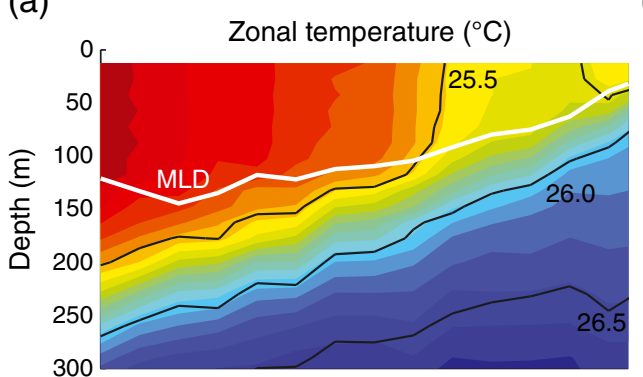

(c)

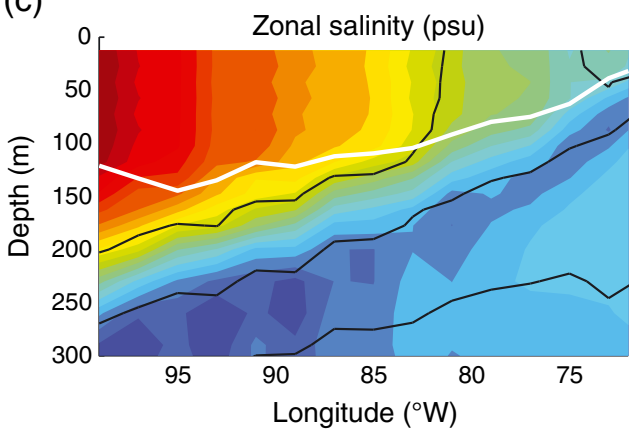

(b)

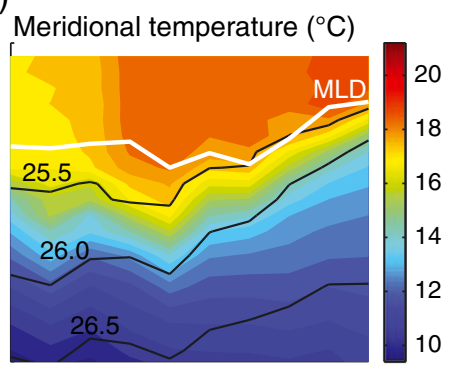

(d)

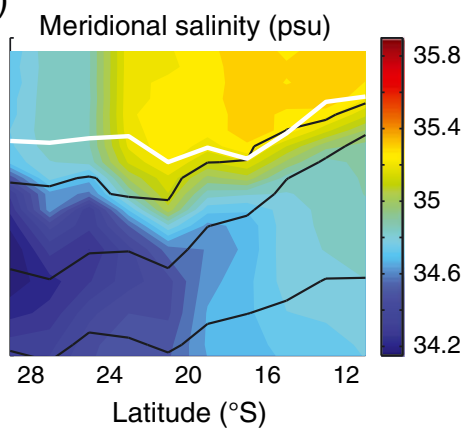

Figure 2. Composite winter Argo sections in the SEP of (a) zonal and (b) meridional temperature and (c) zonal and (d) meridional salinity. The zonal and meridional sections were computed along $20^{\circ} \mathrm{S}$ and $85^{\circ} \mathrm{W}$, respectively, by averaging Argo profiles from August, September, and October in $2^{\circ}$ (alongsection) by $6^{\circ}$ (cross section) bins. The average MLD (white line) in each bin is also plotted. Potential density (black lines) is contoured along the $25.5,26.0$, and $26.5 \mathrm{~kg} \mathrm{~m}^{-3}$ isopycnals.

each Argo profile, drifter observation, and UCTD profile; the fields are available on a weekly, $0.25^{\circ}$ grid. Longterm SLA trends were first removed by subtracting a SLA field smoothed with a 200 week-long running mean from the weekly fields. The altimetry data are provided online at http://www.aviso.oceanobs.com. We also used Remote Sensing Systems' optimally interpolated SST fields, produced by blending fields from the TMI and AMSR-E instruments [Wentz et al., 2000]. The product is normalized to approximate nighttime SSTs with an empirical model of diurnal warming [Gentemann et al., 2003], and is available on a daily, $0.25^{\circ}$ grid. This SST product is available at http://www.ssmi.com/. All of the satellite data used in the study extended from $15^{\circ} \mathrm{S}$ to $35^{\circ} \mathrm{S}$ and $70^{\circ} \mathrm{W}$ to $100^{\circ} \mathrm{W}$ and covered the period from October 2000 to April 2011.

[16] The CH2011 eddy census was used to characterize eddy propagation and size, and to identify Argo, drifter, and satellite observations collected within eddies. The product uses filtered AVISO SLA fields to identify eddies, and provides weekly fields containing eddy polarity, amplitude, latitude, longitude, and radius. The census contains eddies with lifetimes of 4 weeks and greater. It is available online at http://cioss.coas.oregonstate.edu/eddies/. We also used the CSIRO Atlas of Regional Seas (CARS) climatology [Ridgway et al., 2002] to compute property anomalies within eddies. The climatology is available online at http://www.marine.csiro.au/ dunn/cars2009/.

\section{Eddy Observations}

[17] An Argo climatology (Figure 2) reveals that the shallowest, coldest, and freshest mixed layers in the SEP are found near the coast. This coastal region, extending 200-300 km from the coast, is characterized by coastal upwelling driven by northward winds [Blanco et al., 2001; Schneider et al., 2003]. The mixed layer is warmer, saltier, and deeper to the west, toward the center of the SEP's subtropical gyre. Evaporation greatly exceeds precipitation in the gyre, creating a salty surface layer known as Subtropical Surface Water. Eastern South Pacific Intermediate Water, identifiable as a shallow salinity minimum layer (SML), exists below the surface layer and shoals toward shore. The SML is a widespread feature of profiles from the SEP [Tsuchiya and Talley, 1998]. It is formed in the eastern south Pacific as low-salinity subantarctic surface waters are subducted below higher salinity waters to the north [Reid, 1973; Schneider et al., 2003; Karstensen, 2004]. Near the coast, the high salinity layer beneath the SML, associated with equatorial subsurface water, corresponds to the poleward Peru-Chile Undercurrent (PCU). The upper-ocean mean flow in the offshore region, which extends about 1500 $\mathrm{km}$ from the coast, is weak and combines the southwestward Ekman transport, driven by the trade winds, with the northwestward gyre-scale mean flow [Chaigneau and Pizarro, 2005a; Colbo and Weller, 2007].

[18] The VOCALS-REx cruise sampled three cyclonic eddies $(\mathrm{C} 1, \mathrm{C} 2$, and $\mathrm{C} 3)$ and two anticyclonic eddies (A1 and A2) (Figure 1). The underway ADCP velocities were consistent with the application of the geostrophic relation to the eddy SLA signature; cyclonic eddies (clockwise rotation) were characterized by SLA lows; anticyclonic eddies (counterclockwise rotation) were centered on SLA highs. These five eddies were all identified in the CH2011 eddy census, and the eddy tracks, from their first identification in 
(a)

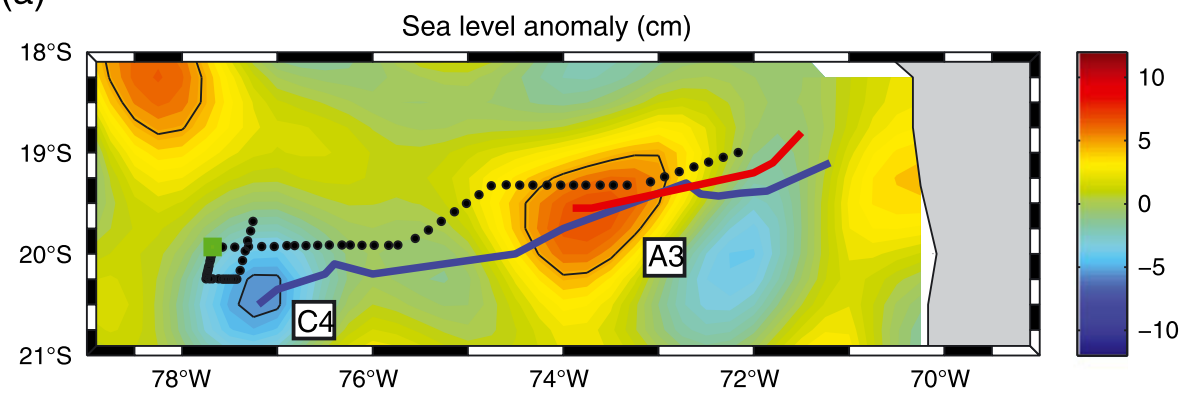

(b)

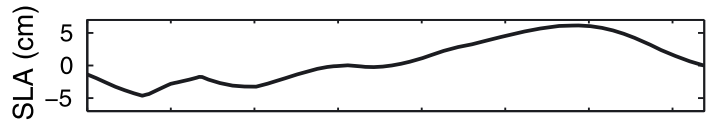

(c)

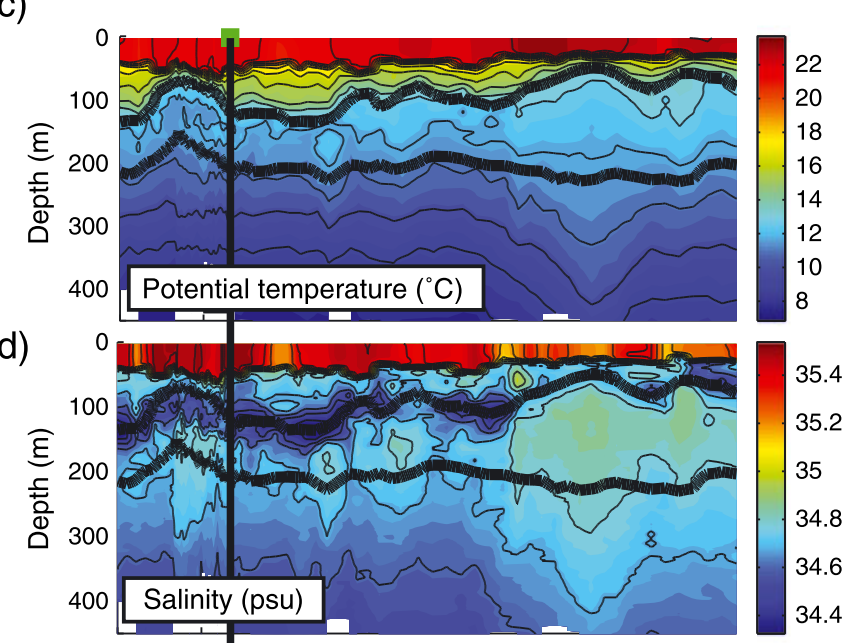

(e)

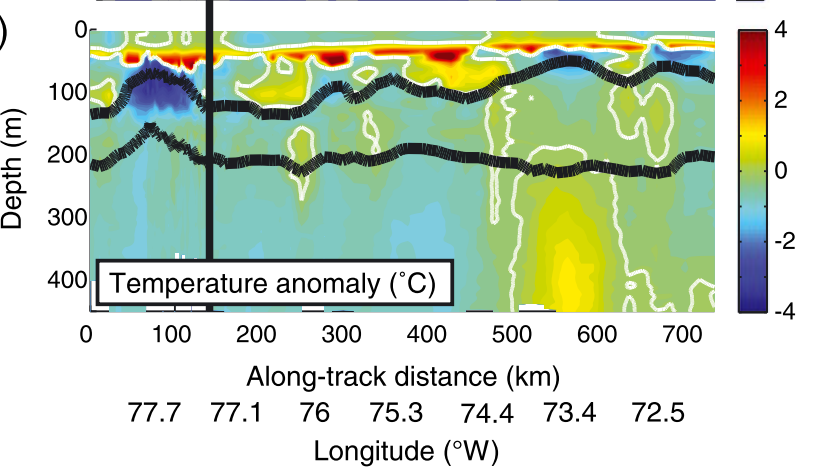

Figure 3. (a) Map of the locations of 71 UCTD profiles collected during the 2011 Stratus cruise. The cruise started offshore and sampled toward the coast over 13-15 April. The colored contours represent the SLA field during the week that included the cruise; the $\pm 5 \mathrm{~cm}$ SLA contours are highlighted by black contours. The locations of cyclonic eddy $\mathrm{C} 4$ and anticyclonic eddy A3 are labeled. The red and blue lines represent the approximate eddy tracks. The along-section SLA (plotted in b) was created by interpolating the SLA field to the locations and times of the UCTD profiles. Sections of (c) temperature, (d) salinity, and (e) temperature anomaly are also plotted; bold black lines mark the 26.0 and $26.5 \mathrm{~kg} \mathrm{~m}^{-3}$ isopycnals. The temperature anomaly was calculated by removing CARS mean profiles interpolated to the UCTD locations and times; the zero temperature anomaly contour is in white. The vertical black line marks where the ship started heading east.

the eddy census until the end of VOCALS-REx, are shown in Figure 1. Two additional eddies, one cyclonic (C4) and one anticyclonic (A3), were observed during Stratus 2011 (Figure 3). The CH2011 eddy census ended in January 2011, so these eddies are not in the database. However, using SLA fields that extended through April 2011, we visually tracked eddy C4 back to a cyclonic eddy identified in CH2011 that originated near the coast in November 2010. Using the same method, anticyclonic eddy A3 appeared to originate near the coast in February 2011. 

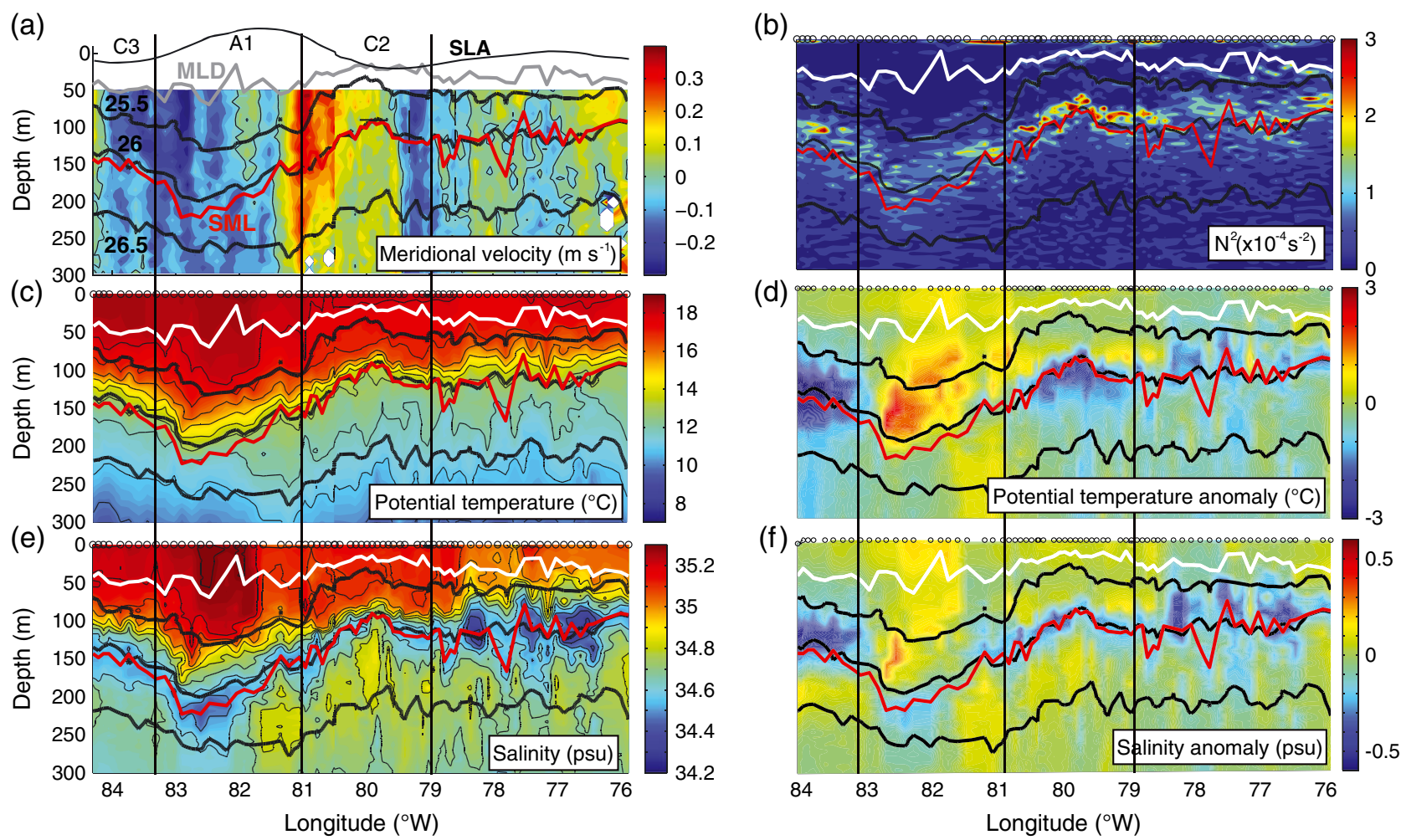

Figure 4. Sections of (a) meridional velocity, (b) $N^{2}$, (c) temperature, (d) temperature anomaly, (e) salinity, and (f) salinity anomaly along $19^{\circ} \mathrm{S}$. The MLD (grey line), SML (red line), and three isopycnals $\left(25.5,26\right.$, and $26.5 \mathrm{~kg} \mathrm{~m}^{-3}$, bold black lines) are plotted in each section. The along-track SLA (thin black line) is plotted above the velocity field. To calculate $N^{2}$ for each profile, temperature, and salinity were first smoothed with three-point running mean. $N^{2}$ was then smoothed with a five-point running mean. The temperature and salinity anomaly were calculated by removing CARS mean profiles interpolated to the UCTD locations and times. The location of the section is plotted in Figure 1.

[19] The synoptic observations collected during VOCALS-REx and Stratus 2011 revealed a more complex upper-ocean structure in the SEP than the simplified Argo climatological description. Much of this variation was due to the cyclonic and anticyclonic eddies sampled during each cruise, as the eddies modulated the hydrographic features of the SEP, including the depth and salinity of the SML, which followed the $26.0 \mathrm{~kg} \mathrm{~m}^{-3}$ isopycnal (Figures 3-5). In general, isopycnals shoaled near the surface in cyclonic eddies, whereas the isopycnal displacements were more varied in anticyclonic eddies (Figures 3-5). The stratification directly under the mixed layer was higher in the eddies that featured shoaling near-surface isopycnals, which were mostly cyclones (Figures 4 and 5). Similarly, the highest stratification values during Stratus 2011 were observed in the eddies, as the SML shoaled within both eddies.

[20] Many eddies featured high salinity layers along the $26.5 \mathrm{~kg} \mathrm{~m}^{-3}$ isopycnal, particularly anticyclonic eddy A3 (Figure $3 \mathrm{~d}$ ) and, close to its center, cyclonic eddy $\mathrm{C} 1$ (Figure 6d); this salinity structure suggests that the eddies trapped high-salinity PCU water near the coast and transported it offshore. These results are consistent with previous findings for anticyclones [Johnson and McTaggart, 2010; Chaigneau et al., 2011; Colas et al., 2011], but such features have not been previously observed in cyclones. Besides eddy $\mathrm{C} 1$, higher salinity values (approximately $34.9 \mathrm{psu}$ ) along the $26.5 \mathrm{~kg} \mathrm{~m}^{-3}$ isopycnal were also evident in cyclonic eddy $\mathrm{C} 2$ (Figures $4 \mathrm{e}$ and $4 \mathrm{f}$ at $80^{\circ} \mathrm{W}$, between approximately 150 and $200 \mathrm{~m}$ depth) and cyclonic eddy C4 (Figure $3 \mathrm{~d}$ at $77.7^{\circ} \mathrm{W}$, between approximately 150 and $300 \mathrm{~m}$ depth), as well as in anticyclonic eddy A1 (Figures $4 \mathrm{e}$ and $4 \mathrm{f}$ at $81.5^{\circ} \mathrm{W}$, between approximately 200 and $250 \mathrm{~m}$ depth).

[21] We considered fluid trapping in eddy $\mathrm{C} 1$ by examining the velocity and 2-D Ertel potential vorticity (EPV) structures of eddy $\mathrm{C} 1$, both of which suggest that the eddy trapped water to a depth of approximately $450 \mathrm{~m}$. The diameter of the high-velocity subsurface eddy core, here defined as the region characterized by the pinching of the 26.5 and $27.0 \mathrm{~kg} \mathrm{~m}^{-3}$ isopycnals, was small, approximately $30 \mathrm{~km}$ (Figure 6). The eddy size, $30 \mathrm{~km}$ at the subsurface core and $100 \mathrm{~km}$ at the surface, was similar to the sizes reported by Chaigneau and Pizarro [2005a, 2005b] and Chelton et al. [1998]. The subsurface velocity core, at approximately 200 to $400 \mathrm{~m}$ depth, had a rotational speed of $0.3 \mathrm{~m} \mathrm{~s}^{-1}$ and corresponded to the high salinity core of PCU water. The eddy trapping depth, above which the eddy traps fluid, is the depth at which the tangential velocity at the edge of the $30 \mathrm{~km}$ eddy core equals the propagation speed of the eddy [Flierl, 1981]. We calculated a propagation speed of approximately $3 \mathrm{~cm} \mathrm{~s}^{-1}$ for eddy $\mathrm{C} 1$ with a Hovmöller SLA diagram, indicating a trapping depth beyond $450 \mathrm{~m}$ (Figure 6). This is considerably deeper than the average $280 \mathrm{~m}$ trapping depth 


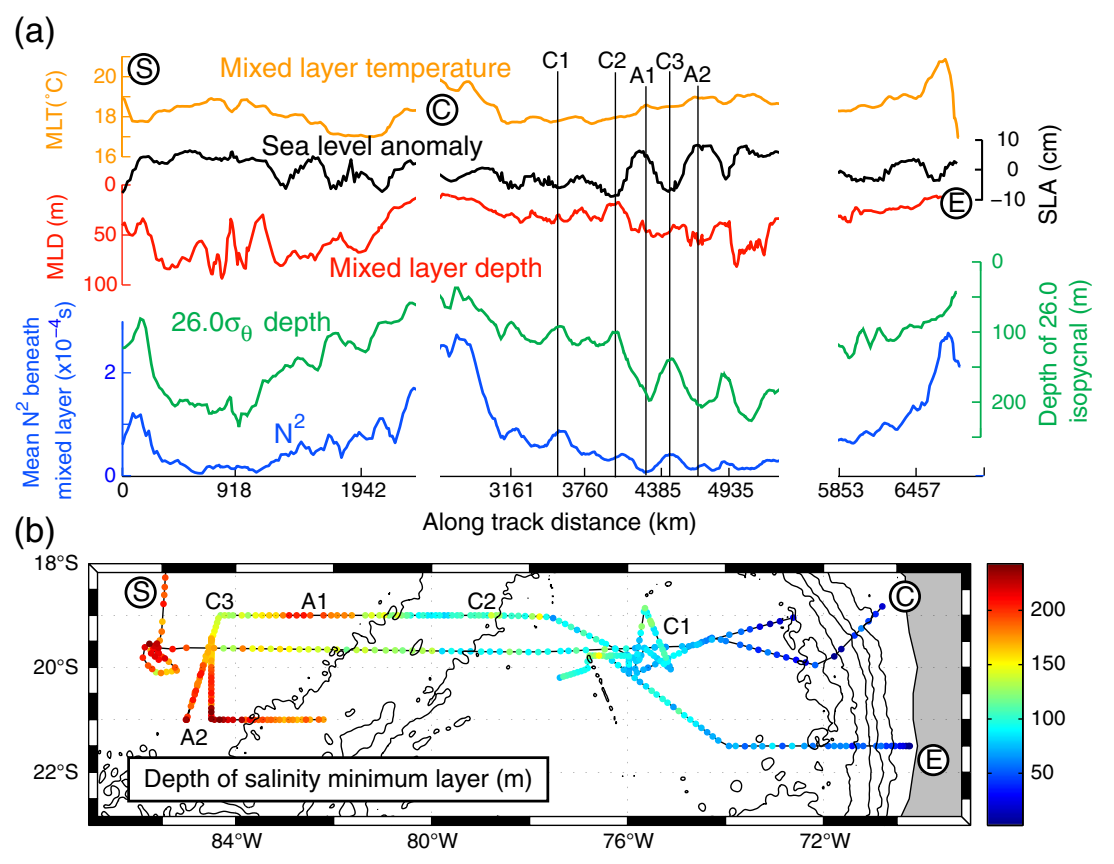

Figure 5. (a) The mixed-layer temperature (MLT, orange line), SLA (black line), MLD (red line), depth of the $26.0 \mathrm{~kg} \mathrm{~m}^{-3}$ isopycnal (green line), and mean stratification (squared buoyancy frequency) beneath the mixed layer (blue line) are plotted against along-track distance. The $26.0 \mathrm{~kg} \mathrm{~m}^{-3}$ isopycnal closely tracks the salinity minimum layer. The mean stratification is calculated over $40 \mathrm{~m}$ beneath the mixed layer. The MLT, $26.0 \mathrm{~kg} \mathrm{~m}^{-3}$ isopycnal depth, and mean stratification fields were smoothed with a running-mean filter that used all profiles within $40 \mathrm{~km}$ of each UCTD profile. The black vertical lines denote the centers of the eddies identified in Figure 1; the eddy locations are also labeled in (b) the salinity minimum layer depth map. The bathymetry is contoured in black at $2000 \mathrm{~m}$ intervals. In Figures 5a and 5b, the circles denote the start (S), the first coastal stations (C), and the cruise's end (E).

computed by Chaigneau et al. [2011] using the same method and a composite cyclonic eddy assembled from Argo profiles. Early et al. [2011], in a numerical study of idealized eddies, determined that an eddy's inner core, defined by the zero relative vorticity contour, trapped fluid from the eddy's origin. Applying this relative vorticity criterion to eddy $\mathrm{C} 1$, the trapped fluid in the eddy core extended to a depth of $450 \mathrm{~m}$ (Figure 7c), in good agreement with the velocity analysis.

[22] We calculated the EPV to assess the source regions of water trapped in eddy C1. The EPV was calculated in an eddy-oriented coordinate system following Beal et al. [2006]; the coordinates and velocity were transformed into tangential and radial components, and the origin was located at the center of the eddy, identified as the along-track SLA minimum. The radial velocity was assumed to be zero; this assumption seems reasonable given the velocity field in Figure 6. The density profiles were first averaged to match the ADCP bin size of $16 \mathrm{~m}$. The velocity and density fields were then smoothed twice with $40 \mathrm{~m}$ running-mean filters to remove small scale fluctuations. The EPV was then calculated using:

$$
\mathrm{EPV}=\frac{-g}{\rho}\left[f \frac{\partial \rho}{\partial z}+\left(\frac{\partial v_{t}}{\partial r} \frac{\partial \rho}{\partial z}-\frac{\partial v_{t}}{\partial z} \frac{\partial \rho}{\partial r}\right)\right]
$$

where $g$ is the acceleration due to gravity, $\rho$ is the potential density, $f$ is the Coriolis parameter, $z$ is the vertical coordinate (positive downward), $r$ is the radial coordinate, and $v_{t}$ is the eddy tangential velocity. The first term on the right-handside represents the planetary vorticity term. The second and third terms are related to the horizontal and vertical shears, respectively.

[23] Eddy C1 was characterized by low EPV $(<0.5 \times$ $\left.10^{-9} \mathrm{~s}^{-3}\right)$ in the eddy core between 150 and $250 \mathrm{~m}$ depth (Figure 7). This low EPV layer had values similar to those observed in the coastal section along $21.5^{\circ} \mathrm{S}$ (not shown), suggesting that water in this depth range had been transported offshore by the eddy, as EPV is conserved in the ocean interior in the absence of internal heating and stress divergence.

[24] The high-salinity PCU water observed in many eddies during VOCALS-REx and Stratus 2011 suggest that cyclonic and anticyclonic eddies in the SEP can trap coastal water and transport it offshore. The velocity, EPV, and salinity structure of eddy $\mathrm{C} 1$ suggest that the eddy trapped fluid to a depth of $450 \mathrm{~m}$, deeper than previously observed for cyclonic eddies in the SEP. Cyclonic eddies with deep ( $\sim 300 \mathrm{~m})$ maximum-velocity cores similar to eddy $\mathrm{C} 1$ have not been previously observed in the SEP; we attribute this to the small size of the features, which makes them difficult to sample with Argo floats. However, the intensified surface expression and deep extension of eddy $\mathrm{C} 1$ 's velocity structure were largely consistent with previous studies, which have shown that cyclones tend to be surface intensified, but also have deep signatures [Chaigneau and Pizarro, 2005a; Colas et al., 2011; Chaigneau et al., 2011]. 
(a)

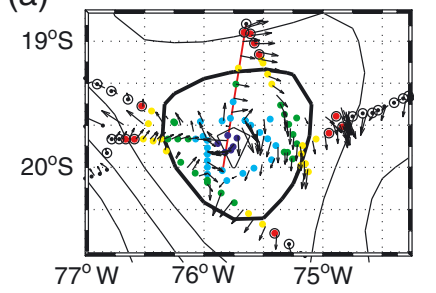

(b)

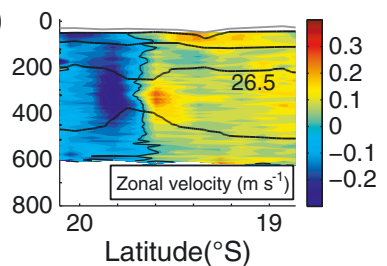

(c)

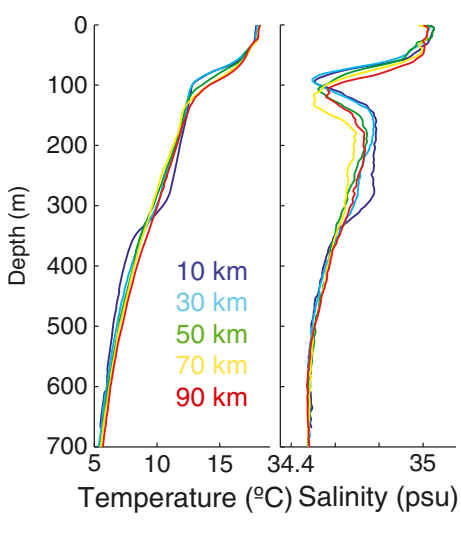

(e)

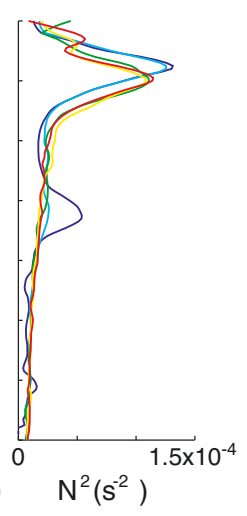

Figure 6. Velocity (a) map and (b) section from the survey of cyclonic eddy $\mathrm{C} 1$. The mean currents (black arrows) in (a) are averaged over $50-650 \mathrm{~m}$ depth. The SLA is contoured at $2.5 \mathrm{~cm}$ intervals; the bold contour corresponds to a $-5 \mathrm{~cm}$ SLA anomaly. The UCTD stations (dots) are colored according to their distance from the eddy center, with radial bins of width $20 \mathrm{~km}$, starting at the center (blue closest to center, red farthest from center). The zonal velocity of the cruise track highlighted in red is plotted in (b); potential density is contoured at $0.5 \mathrm{~kg} \mathrm{~m}^{-3}$ intervals. The mean eddy (c) temperature, (d) salinity, and (e) stratification (squared buoyancy frequency) profiles are calculated by averaging the profiles in each radial bin. The color of the profiles in c,d, and e corresponds to the station colors in (a) that indicate distance from the eddy center. The stratification was binned at 5 meter intervals and then smoothed with a 5-point running mean.

\section{Eddy Temperature Anomalies}

[25] While both cyclonic and anticyclonic eddies observed during VOCALS-REx and Stratus 2011 frequently exhibited high-salinity PCU water at depth, they exhibited contrasting net and near-surface (within and immediately below the mixed layer) temperature anomalies. As examples, the anomalous temperature and salinity fields associated with eddy $\mathrm{C} 1$ (Figure 8) were calculated by subtracting mean temperature and salinity profiles from the CARS climatology from the eddy profiles shown in Figure 6. Temperature anomalies for cyclonic eddy $\mathrm{C} 4$ and anticyclonic eddy A3 were obtained by interpolating the CARS climatology to the Stratus 2011 UCTD locations (Figure 3).

[26] The net anomaly of cyclonic eddy $\mathrm{C} 1$ was cool and fresh (Figures $8 \mathrm{a}$ and $8 \mathrm{~b}$ ), whereas the net anomaly of anticyclonic eddy A3 was warm and saline (Figure 3), in general agreement with previous studies [Chaigneau et al., 2011; Colas et al., 2011]. The total depth-integrated temperature anomalies of the eddies, however, could not be calculated because of the limited vertical extent of the UCTD data. Beneath $300 \mathrm{~m}$ eddy $\mathrm{C} 1$ had an extensive cold and fresh anomaly, whereas no deep, cool anomaly was evident in cyclonic eddy $\mathrm{C} 4$, perhaps because the cruise only sampled the eddy's periphery.

[27] Cyclonic eddies $\mathrm{C} 4$ and $\mathrm{C} 1$ both exhibited cool nearsurface anomalies below and within their mixed layers (Figures 3 and 8). The near-surface doming of isopycnals within eddy $\mathrm{C} 1$ created a cool (approximately $-1^{\circ} \mathrm{C}$ ) and fresh anomaly at approximately $100 \mathrm{~m}$ depth within $60 \mathrm{~km}$ of the eddy center. The doming also compressed the isopycnals near the surface, resulting in higher stratification (a)

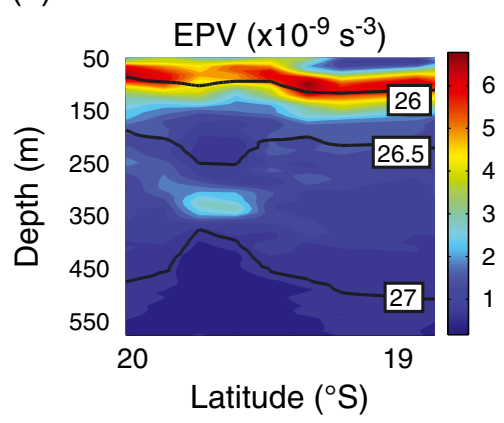

(b)

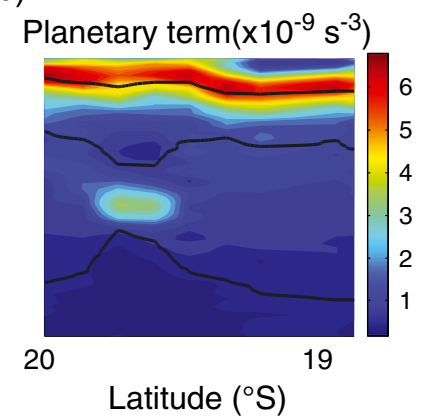

(c)

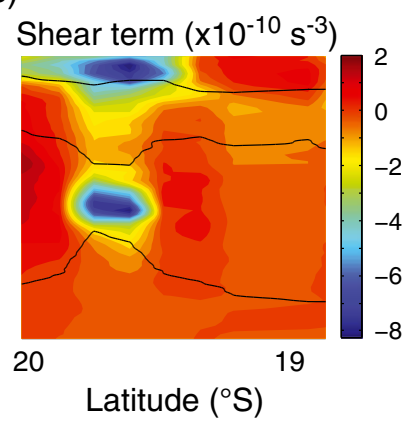

Figure 7. Section of (a) Ertel potential vorticity (EPV) through eddy C1, as well as the (b) planetary and (c) shear components of the EPV. The EPV is shown for the velocity section plotted in Figure 6. The potential density is contoured along the $26,26.5$, and $27 \mathrm{~kg} \mathrm{~m}^{-3}$ isopycnals. Note that the color bar in Figure $7 \mathrm{c}$ is an order of magnitude smaller than that for the other plots. 
(a)

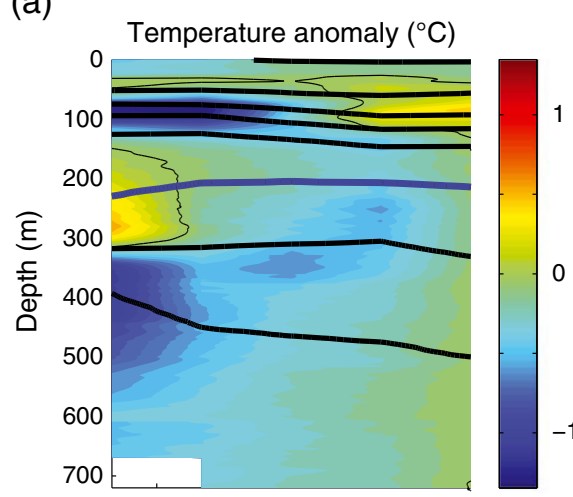

(c)

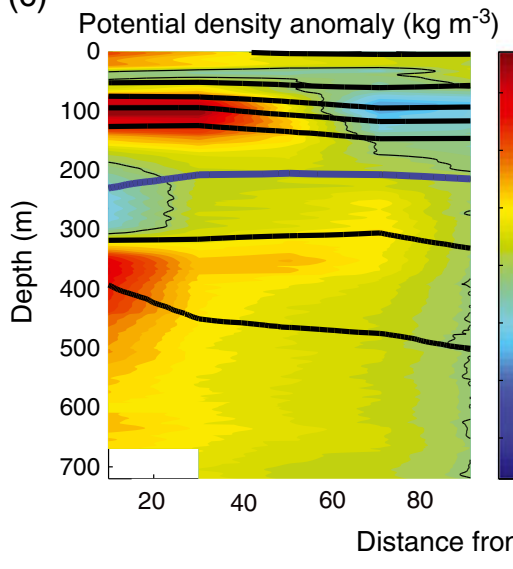

(b)

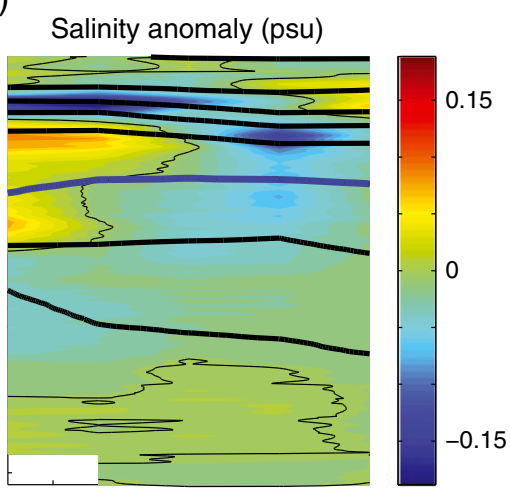

(d)

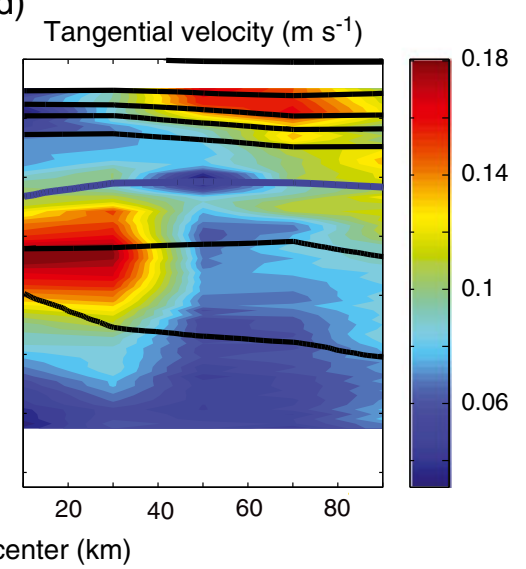

Figure 8. Mean (a) temperature anomaly, (b) salinity anomaly, (c) potential density anomaly, and (d) tangential velocity of eddy $\mathrm{C} 1$. The anomalous fields were derived by subtracting the mean eddy profiles in Figure 6 from the CARS climatology. A positive anomaly corresponds to an eddy that is warmer, saltier, or denser than the mean profile. The eddy potential density is contoured at $0.25 \mathrm{~kg} \mathrm{~m}^{-3}$ intervals (thick black contours); the $26.5 \mathrm{~kg} \mathrm{~m}^{-3}$ isopycnal is in blue.

at $100 \mathrm{~m}$ in the two profiles nearest to the eddy center (Figure 6e). This shoaling of near surface isopycnals was consistent with the other cyclonic eddies observed during VOCALS-REx (Figure 5), as well as with eddy C4 observed during Stratus 2011 (Figure 3e). Eddy C4 featured a cool anomaly of approximately $-3^{\circ} \mathrm{C}$ beneath the mixed layer, extending from approximately 50 to $150 \mathrm{~m}$ depth. Although the magnitude of the signal was small, the mixed layers of cyclonic eddies observed during VOCALS-REx and Stratus 2011 tended to be cooler than the surrounding mixed layers, whereas the mixed layers of anticyclonic eddies tended to be warmer (Figures $3 \mathrm{c}$ and $5 \mathrm{a}$ ); for example, the mixed layer within cyclonic eddy $\mathrm{C} 1$ was $0.2^{\circ} \mathrm{C}$ cooler than outside of the eddy.

[28] The anticyclonic eddies observed during VOCALSREx and Stratus 2011 exhibited more variable near-surface anomalies than the cyclonic eddies. Some doming of nearsurface isopycnals was evident in eddy A3, creating a cool anomaly of approximately $-2^{\circ} \mathrm{C}$ beneath the mixed layer (Figure 3), but doming was not observed in eddies A1 or A2 (Figures 4 and 5). In fact, the deepest SML along the $19^{\circ} \mathrm{S}$ VOCALS-REx section was observed in anticyclonic eddy A1 (Figure 4). The anticyclonic eddies observed during the cruises also tended to have warmer mixed layers than the cyclonic eddies. The warmest mixed layers of Stratus 2011 were observed in eddy A3 (Figure 3c). Eddy A2 had mixed-layer temperatures approximately $0.4^{\circ} \mathrm{C}$ warmer than the surrounding waters (Figure 5a).

[29] To summarize the synoptic eddy observations, the hydrographic structures of the eddies observed during VOCALS-REx and Stratus 2011 provided evidence for eddy trapping within both cyclonic and anticyclonic eddies. Previous studies have identified eddy trapping in anticyclones [Johnson and McTaggart, 2010; Chaigneau et al., 2011], but not in cyclones. In general, cyclonic eddies were characterized by cool net anomalies and cool anomalies beneath the mixed layer due to the doming of isopycnals; the mixed layers of cyclonic eddies also tended to be cooler than neighboring mixed layers. Anticyclonic eddies were associated with warm net anomalies and variable anomalies in and below the mixed layer. These anomalies were largely consistent with previous studies, but had never been observed in such detailed synoptic sections. Similar to our study, Colas et al. [2011], Kurian et al. [2011], and Chaigneau et al. [2011] found cool near-surface anomalies in cyclones. Colas et al. [2011] and Kurian et al. [2011] identified warm near-surface anomalies in anticyclones, as did our study, whereas Chaigneau et al. [2011] reported cool near-surface anomalies in anticyclones.

[30] The eddy structures observed during VOCALSREx and Stratus 2011 suggest possible mechanisms through 
Table 1. Number of Cyclonic and Anticyclonic Eddies Sampled in Each Data Set, as Well as the Mean ( \pm Standard Error) Eddy Temperature Anomaly (TA)

\begin{tabular}{lcccc}
\hline \multicolumn{1}{c}{ Data Source } & Number of Cyclonic & Number of Anticyclonic & Cyclonic TA & Anticyclonic TA \\
\hline VOCALS-REx & 3 & 2 & $-0.06 \pm 0.10$ & $0.36 \pm 0.11$ \\
Argo mixed layer & 142 & 186 & $-0.34 \pm 0.06$ & $0.20 \pm 0.05$ \\
Argo 100-700 m & 142 & 186 & $-0.48 \pm 0.03$ & $0.38 \pm 0.02$ \\
Drifters & 384 & 332 & $-0.22 \pm 0.04$ & $0.27 \pm 0.05$ \\
Satellite & 1032 & 1071 & $-0.28 \pm 0.02$ & $0.18 \pm 0.02$ \\
\hline
\end{tabular}

which eddies could cool the mixed layer of the SEP. The doming of near-surface isopycnals within eddies, likely due to eddy trapping at depth, could promote the mixing of deeper, colder water into the surface layer by bringing cooler water closer to the surface (as seen, for example, in eddies $\mathrm{C} 1$ and A4). Likewise, the lower stratification beneath the mixed layer (as seen, for example, in eddies A1 and A2) could make it easier to entrain deeper, colder water into the mixed layer, although it would be distributed throughout a deeper layer. Without more extensive subsurface observations, we cannot evaluate these mechanisms, but we can use various data sources to search for a relationship between eddy SLA and upper-ocean temperature.

\section{Eddy SLA-SST Relationship}

[31] If eddies are indeed cooling the surface layer of the SEP, then we might expect them to be associated with cooler SSTs relative to mean conditions, especially if they are transporting cool, coastal water in their cores. We therefore searched for a relationship between eddies and upper-ocean temperature in a variety of data sets, including VOCALSREx profiles, Argo profiles, drifter records, and satellite SST fields. We used CH2011 to identify observations collected within eddies, and restricted our analysis to these observations. We interpolated AVISO SLA fields to each observation and used the CARS climatology to represent mean conditions. The climatology was interpolated to the date and location of each observation, and then subtracted from each observation to calculate temperature anomaly. The satellite SST anomaly was calculated in a similar manner, although it used an annual climatology constructed from the 10 years of satellite SST data. Both the SST fields and the SST climatology were averaged into weekly fields corresponding to the SLA and CH2011 fields. For each week, we identified all of the eddies in $\mathrm{CH} 2011$ and computed the spatial mean SST anomaly within each eddy. We also averaged the SLA within each eddy.

[32] For each of the four data sets, the mean temperature anomaly and standard error (SE) of cyclonic and anticyclonic eddies was calculated by averaging all of the temperature anomaly observations with SLA $<-5 \mathrm{~cm}$ and SLA $>5 \mathrm{~cm}$, respectively. In general, changing the $\pm 5 \mathrm{~cm}$ cutoff changed the magnitude, but not the sign, of the mean temperature anomalies. The SE of the mean temperature anomaly was calculated using $\mathrm{SE}=\sigma / \sqrt{n}$, where $\sigma$ is the standard deviation of the temperature anomaly and $n$ is the number of cyclonic or anticyclonic eddies observed in the data set; multiple observations from within one eddy at any point in its lifetime were counted as one observation. The number of anticyclonic and cyclonic eddies observed in each data set, as well as their temperature anomalies, are listed in Table 1.

[33] On average, the mixed layers of the three cyclonic eddies observed during VOCALS-REx were slightly colder than mean mixed layers $\left(-0.06^{\circ} \pm 0.10^{\circ} \mathrm{C}\right)$, whereas the mixed layers of the two anticyclonic eddies were considerably warmer than mean mixed layers $\left(0.36^{\circ} \pm 0.11^{\circ} \mathrm{C}\right)$ (Figure 9 and Table 1). A student $t$-test performed on the VOCALS-REx temperature anomaly distribution confirmed that the cyclonic and anticyclonic eddies had significantly different mean temperature anomalies; this was true for all of the subsequent data sets as well.

[34] Expanding from the synoptic VOCALS-REx observations to the broader Argo data set, we again found that cyclonic eddies were characterized by anomalously cool mixed layers $\left(-0.34^{\circ} \pm 0.06^{\circ} \mathrm{C}\right)$, whereas anticyclonic eddies had anomalously warm mixed layers $\left(0.20^{\circ}\right.$ $\pm 0.05^{\circ} \mathrm{C}$ ) (Figure 10a and Table 1). Similarly, over the 100-700 m depth range, cyclonic eddies had negative mean temperature anomalies $\left(-0.48^{\circ} \pm 0.03^{\circ} \mathrm{C}\right)$ and anticyclonic eddies had positive mean temperature anomalies $\left(0.38^{\circ}\right.$ $\pm 0.02^{\circ} \mathrm{C}$ ) (Figure 10b and Table 1); the signs of these anomalies are consistent with the findings of Chaigneau et al. [2011] and Colas et al. [2011]. The mixed-layer anomalies of the eddies observed during VOCALS-REx and Stratus 2011 were consistent with the Argo observations. On

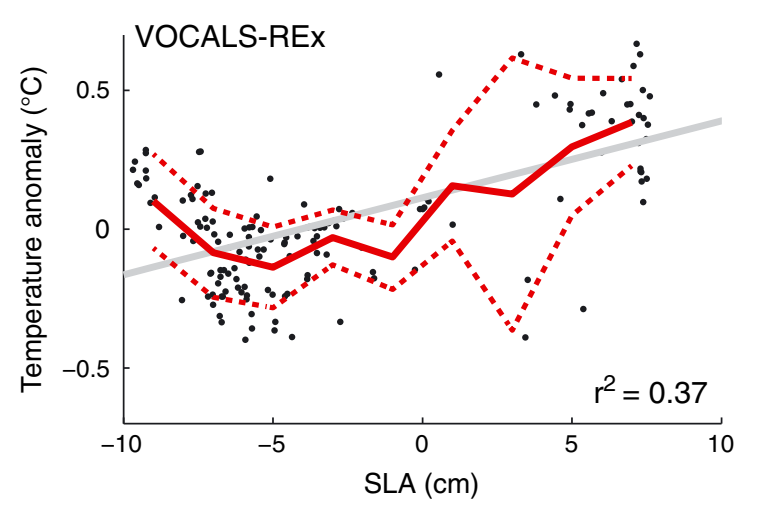

Figure 9. VOCALS-REx mixed-layer temperature anomaly plotted against SLA (black dots). The mixed-layer temperature anomaly was calculated using 152 UCTD profiles from VOCALS-REx observations of three cyclonic and two anticyclonic eddies. The bold red line is the mean temperature anomaly calculated for SLA bins of $2 \mathrm{~cm}$ width; the dashed red lines represent plus or minus the standard deviation. The grey line represents the least-squares fit to the data; the fraction of variance $\left(r^{2}\right)$ explained by the fit is also given. 
(a)

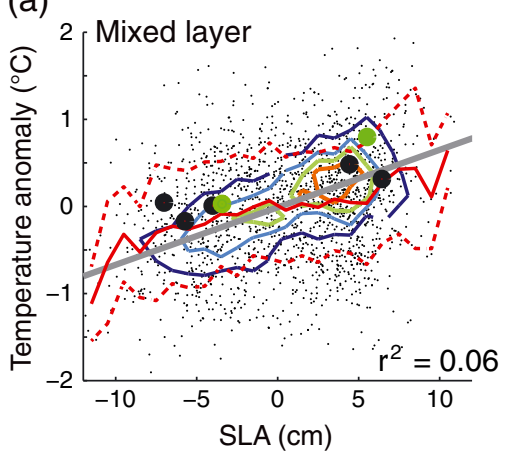

(b)

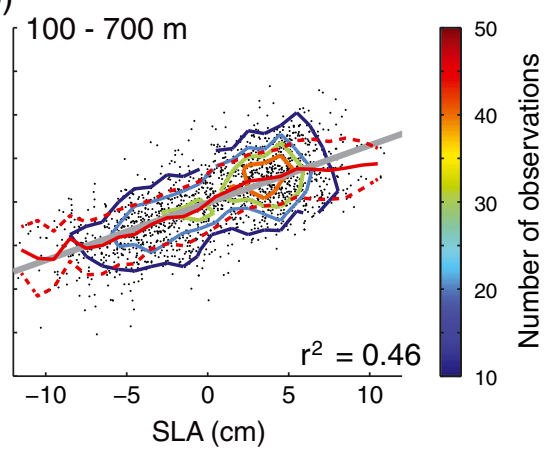

Figure 10. Argo temperature anomalies for the (a) mixed layer and (b) 100-700 m depth layer plotted against SLA (black dots). The bold red line is the mean temperature anomaly calculated for SLA bins of $1 \mathrm{~cm}$ width; the dashed red lines represent \pm 1 standard deviation. The grey line represents the least-squares fit to the data; the fraction of variance $\left(r^{2}\right)$ explained by the fit is also given. The colored contours represent the number of observations in $1 \mathrm{~cm}$ by $0.25^{\circ} \mathrm{C}$ bins. The mean mixed-layer temperature anomalies from the eddies surveyed during VOCALS-REx (large black dots) and Stratus 11 (large green dots) are also plotted. The plots contain data from 1647 Argo profiles collected in 142 cyclonic and 186 anticyclonic eddies since 2003.

average, the cyclonic eddies observed during VOCALS-REx had smaller mixed-layer temperature signals than the eddies observed by Argo. This was likely a seasonal effect, as the Argo temperature anomalies were weakest in winter and early spring.

[35] Drifter data yielded mean eddy temperature anomalies similar to the VOCALS-REx and Argo data sets (Figure 11a and Table 1). Cyclonic eddies were cooler than mean conditions $\left(-0.22^{\circ} \pm 0.04^{\circ} \mathrm{C}\right)$ and anticyclonic eddies were warmer than mean conditions $\left(0.27^{\circ} \pm 0.05^{\circ} \mathrm{C}\right)$.

[36] In the satellite SST data, cyclonic eddies were again colder than mean conditions $\left(-0.18^{\circ} \pm 0.02^{\circ} \mathrm{C}\right)$ and anticyclonic eddies were warmer than mean conditions $\left(0.28^{\circ} \pm\right.$ $0.02^{\circ} \mathrm{C}$ ) (Figure $11 \mathrm{~b}$ and Table 1$)$. The satellite SST anomalies of the five eddies sampled during VOCALS-REx were consistent with the in situ observations; for example, the satellite SST anomaly of anticyclonic eddy A 1 was $0.1^{\circ} \mathrm{C}$ on
19 November, 4 days after it was surveyed during VOCALSREx. In general, the time series of SST anomaly for any individual eddy was extremely variable; this was to be expected, as many processes other than coherent eddy-core transport influence SST. The satellite SST anomalies did not vary with longitude, indicating that the eddies equilibrated quickly with the atmosphere.

[37] The anticyclonic and cyclonic eddies identified in $\mathrm{CH} 2011$ occurred in similar numbers and had similar radii averaged over the entire SEP (Figure 12 and Table 2). To identify any regions in the SEP where either anticyclonic or cyclonic eddies predominated, we counted the number of final eddy positions in $1^{\circ} \times 1^{\circ}$ bins; in essence, this was a crude estimate of where the water trapped in decaying eddies was dispersed. Taking the difference between the number of anticyclonic and cyclonic eddies in each bin should have revealed any regions where one type of eddy (a)

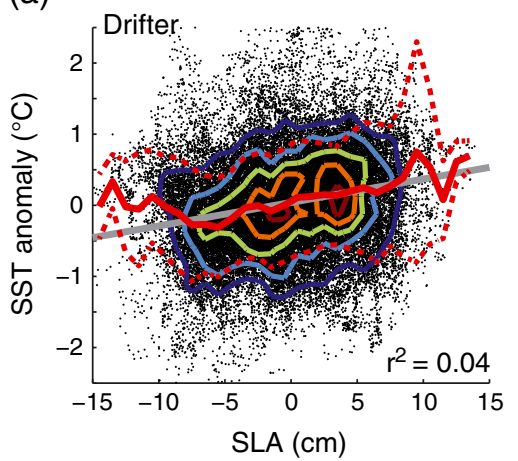

(b)

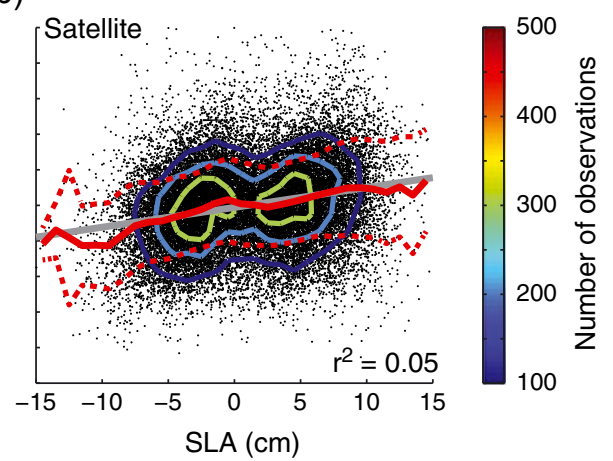

Figure 11. SST anomaly plotted against SLA (black dots) for (a) drifter observations and (b) satellite fields. The bold red lines represent the mean SST anomalies calculated for SLA bins of $1 \mathrm{~cm}$ width, plus or minus the standard deviation (dashed red lines). The grey line represents the least-squares fit to the data; the fraction of variance $\left(r^{2}\right)$ explained by the fit is also given. The colored contours represent the number of observations in $1 \mathrm{~cm}$ by $0.25^{\circ} \mathrm{C}$ bins. The drifters collected 43708 observations of 384 cyclones and 332 anticyclones since 2000. The satellite fields plot includes data from 28,470 observations of 1032 cyclonic and 1071 anticyclonic eddies since 2000. 
(a)

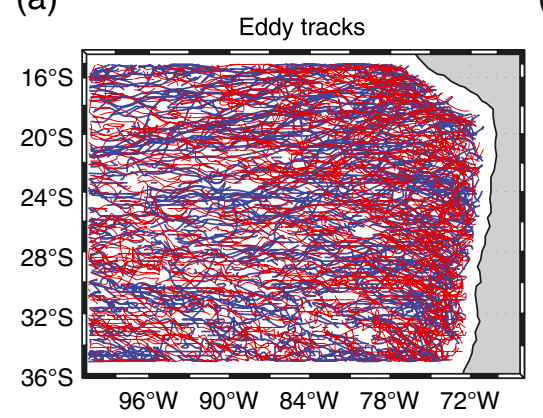

(b)

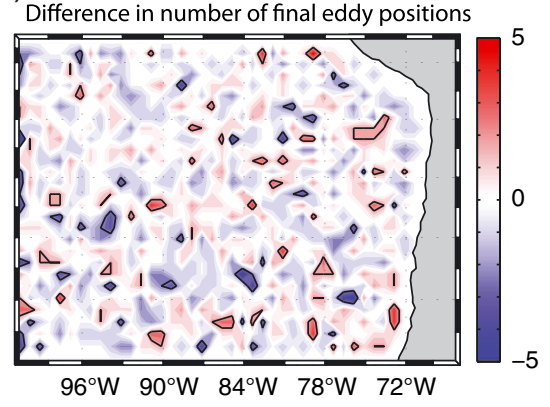

(c)

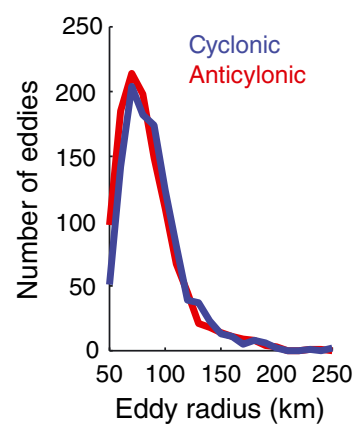

Figure 12. Maps of (a) cyclonic (blue lines) and anticyclonic (red lines) eddy tracks from CH2011, as well as (b) the difference in the number of final (meaning the eddy is no longer identified in CH2011) eddy positions in $1^{\circ} \times 1^{\circ}$ bins (blue indicates more cyclonic eddies, red indicates more anticyclonic eddies). The black contours indicate differences of two or more eddies. (c) The distribution of cyclonic (blue line) and anticyclonic (red line) eddy radii for the region.

occurred more frequently. No regions in the SEP exhibited an eddy preference (Figure 12b). On average, cyclonic eddies had longer lifetimes (14.4 weeks) than anticyclonic eddies (12.7 weeks). These eddy statistics were largely similar to those reported in other studies of the SEP [Colas et al., 2011; Chaigneau et al., 2011]. These studies relied on different SLA eddy tracking algorithms, and so would be expected to have slightly different results. Altimetry cannot provide a complete census of SEP eddies, as the smoothing of altimetry fields likely prohibits the identification of small eddies [Chaigneau and Pizarro, 2005a; CH2011]. Besides the number of eddies, the distributions of cyclonic and anticyclonic eddy radii were also remarkably similar in CH2011 (Figure 12c and Table 2). The average cyclonic and anticyclonic eddy radii were 86 and $85 \mathrm{~km}$, respectively. Chaigneau et al. [2011] found that the average cyclonic and anticyclonic eddy radii differed by less than $5 \mathrm{~km}$ in the SEP. Kurian et al. [2011] found that cyclonic and anticyclonic eddy radii were similar in the California current system, a dynamically similar region.

[38] This eddy SLA-SST analysis indicates that eddies in the SEP do not coherently transport cool, coastal water offshore within their cores in the surface layer. VOCALSREx and Argo profiles, drifters records, and satellite SST data consistently show that cyclonic eddies are associated with cooler temperatures than mean conditions and that anticyclonic eddies are associated with warmer temperatures (Figures 9-11 and Table 1). The surface temperature anomalies of the eddies are small, on the order of $0.5^{\circ} \mathrm{C}$. Student $t$-tests confirm that the mean temperature anomalies of cyclonic and anticyclonic eddies (SLA $<-5 \mathrm{~cm}$ and SLA $>5 \mathrm{~cm}$, respectively) are significantly different within each data set. Cyclonic and anticyclonic eddies occurred in similar numbers and have similar radii, at least according to CH2011. The discrepancy in the number of cyclones and anticyclones observed by Argo and drifters (Table 1) is likely due to differences in the typical velocity structure of cyclonic and anticyclonic eddies. Cyclones tend to be surface intensified, and so could be more likely to entrain drifters, whereas anticyclones tend to have deeper velocity cores, and so might be more likely to trap Argo floats.

\section{Surface-Layer Eddy Heat Flux}

[39] We used weekly satellite SLA and SST fields to estimate the eddy heat flux divergence $(Q)$ in the surface layer by evaluating:

$$
Q=-\rho c_{p} h \nabla \cdot \overline{\mathbf{v}^{\prime} T^{\prime}},
$$

where the surface-layer eddy temperature fluxes, $\overline{\mathbf{v}^{\prime} T^{\prime}}$, were scaled by the specific heat $\left(c_{p}\right)$, the density $(\rho)$, and the surface-layer thickness $(h)$. The surface-layer eddy temperature fluxes were calculated as the long-term averages of correlations between velocity $(v)$ and temperature $(T)$ fluctuations about the background state:

$$
\overline{\mathbf{v}^{\prime} T^{\prime}}=\overline{(\mathbf{v}-\overline{\mathbf{v}})(T-\bar{T})},
$$

where $\overline{\mathbf{v}}$ and $\bar{T}$ represent the background state, in our case a 16 week mean. Assuming an eddy propagation speed of $3 \mathrm{~cm} \mathrm{~s}^{-1}$ (as found for eddy C1), eddies transit $290 \mathrm{~km}$ over 16 weeks. As eddy radius is typically less than $100 \mathrm{~km}$ (Chaigneau and Pizarro [2005a] and Figure 12c), this background smoothing is therefore appropriate for the majority of eddies. The velocities were calculated using AVISO SLA fields and an assumption of geostrophic

Table 2. Eddy Properties for the Study Period (October 2000 to January 2011) and the Full CH2011 Period (October 1992 to January 2011). The Mean and Standard Deviation Are Given for the Radius and Duration

\begin{tabular}{lcccccc}
\hline & \multicolumn{3}{c}{ October 2000 to January 2011 } & \multicolumn{3}{c}{ October 1992 to January 2011 } \\
& Number & Radius (km) & Duration (weeks) & Number & Radius (km) & Duration (weeks) \\
\hline Cyclonic & 1032 & $86 \pm 25$ & $14.4 \pm 15.3$ & 1787 & $88 \pm 26$ & $14.9 \pm 15.8$ \\
Anticyclonic & 1071 & $85 \pm 28$ & $12.7 \pm 12.5$ & 1900 & $85 \pm 27$ & $12.7 \pm 12.4$ \\
\hline
\end{tabular}




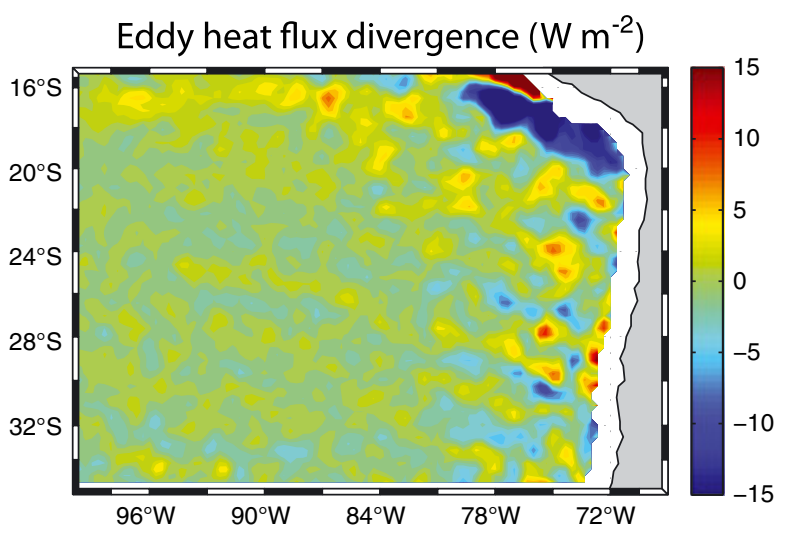

Figure 13. Estimate of the eddy heat flux divergence in the upper $50 \mathrm{~m}$, calculated over the period October 2000 to January 2011.

balance. We assumed that the surface layer was $50 \mathrm{~m}$ thick; this was representative of typical MLDs in the SEP and also the depth used in the heat budget of Zheng et al. [2010] and the eddy study of Chaigneau and Pizarro [2005b].

[40] The surface-layer eddy heat flux divergence was small, $-0.19 \mathrm{~W} \mathrm{~m}^{-2} \pm 1.64 \mathrm{~W} \mathrm{~m}^{-2}$, when averaged over the entire SEP (Figure 13). Offshore, the eddy heat flux divergence was patchy and rarely exceeded $\pm 5 \mathrm{~W} \mathrm{~m}^{-2}$. Larger fluxes occurred in a band near the coast. The large coastal cooling flux at $18^{\circ} \mathrm{S}$, with fluxes of approximately $-15 \mathrm{~W} \mathrm{~m}^{-2}$, corresponded to a region of high eddy kinetic energy [Chaigneau and Pizarro, 2005a] coupled to a large SST gradient due to coastal upwelling. A similar feature appeared in the eddy heat flux calculated by Zheng et al. [2010].

[41] Our satellite-based estimate of the surface eddy heat flux divergence is in agreement with the modeling studies of Zheng et al. [2010] and Toniazzo et al. [2010], which also found patchy eddy fluxes in the SEP; these studies concluded that the eddy fluxes were too variable to contribute to the mean upper-ocean temperature balance. Similarly, Chaigneau and Pizarro [2005b] and Colas et al. [2011] found that the eddy contribution to the SEP's heat budget was small off of Chile.

\section{Discussion and Summary}

[42] This work examines the upper-ocean properties of mesoscale eddies in the southeast Pacific (SEP) with a variety of observations. We used data from the VOCALS-REx and Stratus 2011 cruises to characterize the structure of cyclonic and anticyclonic eddies in the SEP. Observations of elevated salinity along the $26.5 \mathrm{~kg} \mathrm{~m}^{-3}$ isopycnal suggested eddy-core transport at depth within both cyclonic and anticyclonic eddies. Four cyclonic eddies featured a shoaling salinity minimum layer (SML) coupled to a prominent doming of isopycnals near the surface, and higher stratification beneath the mixed layer. Three anticyclonic eddies were more variable; two featured depressed near-surface isopycnals, whereas one exhibited doming isopycnals. In general, cyclonic eddies were characterized by cool net anomalies and cool near-surface anomalies due to the doming of isopycnals beneath the mixed layer. Anticyclonic eddies were associated with warm net anomalies and variable nearsurface anomalies.

[43] In four data sets (VOCALS-REx UCTD profiles, Argo profiles, drifter observations, and satellite data), cyclonic eddies (SLA $<-5 \mathrm{~cm}$ ) were characterized by cooler upper-ocean temperatures relative to mean conditions $\left(0.28^{\circ} \mathrm{C}\right.$ cooler on average for Argo, drifters, and satellite) and anticyclonic eddies (SLA $>5 \mathrm{~cm}$ ) were characterized by warmer upper-ocean temperatures $\left(0.22^{\circ} \mathrm{C}\right.$ warmer on average for Argo, drifters, and satellite). Student $t$-tests performed on the eddy temperature anomaly distributions for all of the data sets confirmed that the mean temperature anomalies of cyclonic and anticyclonic eddies were significantly different.

[44] The contrasting near-surface anomalies observed in cyclonic and anticyclonic eddies during VOCALS-REx and Stratus 2011, as well as in the expanded eddy SLA-SST analysis, are largely consistent with previous studies. In their modeling study, Colas et al. [2011] noted that off Chile, upper-isotherm doming was not prominent in anticyclones, and consequently their model's mean anticyclonic eddy contained a warm anomaly throughout the entire upper $500 \mathrm{~m}$ [Colas et al., 2011, Figure 14]. Colas et al. [2011]'s mean cyclonic eddy had a cool anomaly near the surface, similar to our observations. Similarly, Kurian et al. [2011], in a modeling study of eddies in the California current system, a region with many similarities to the SEP, found cool anomalies in the upper $100 \mathrm{~m}$ of cyclonic eddies and warm anomalies in the upper $100 \mathrm{~m}$ of anticyclonic eddies. Chaigneau et al. [2011] reported cool and fresh anomalies at $100 \mathrm{~m}$ depth in both cyclonic and anticyclonic eddies off of Chile [Chaigneau et al., 2011, Figure 6]; however, the magnitude of the anomaly was much stronger (cooler and fresher) in cyclonic eddies than in anticyclonic eddies. This could be due to differences in the eddy-identification algorithms as well as the study region, and therefore in the Argo profiles that were used to study the eddies.

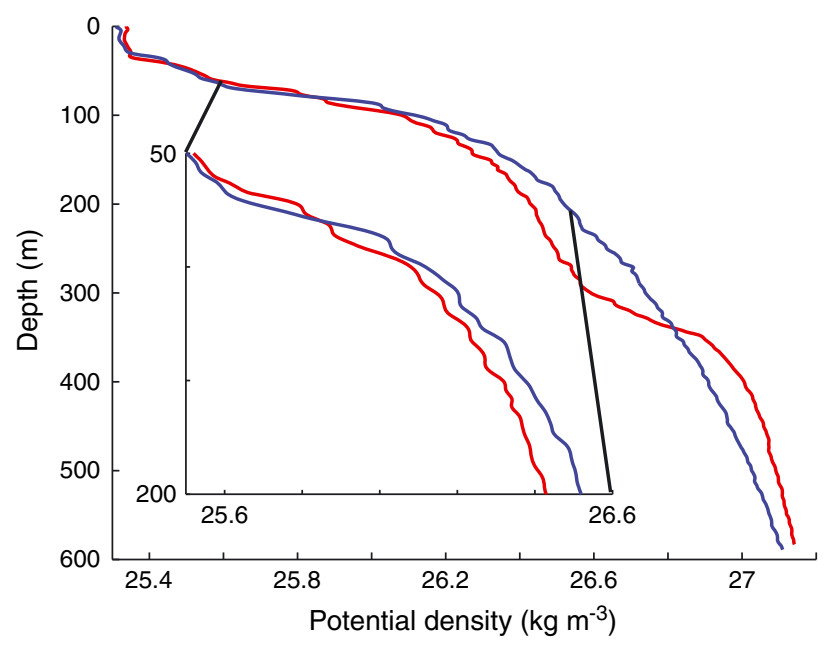

Figure 14. Potential density profiles from VOCALS-REx UCTD station 154 (blue line) and 157 (red line). Profile 154 was collected at the edge of cyclonic eddy $\mathrm{C} 1\left(20.03^{\circ} \mathrm{S}\right.$, $\left.75.85^{\circ} \mathrm{W}\right)$ and profile 157 was collected at the eddy core $\left(19.61^{\circ} \mathrm{S}, 75.78^{\circ} \mathrm{W}\right)$. The inset is zoomed in on the 50 to $200 \mathrm{~m}$ section. 
[45] The systematic differences in eddy upper-ocean temperatures throughout the data sets suggest that some aspect of eddy structure maintains cooler temperatures in the mixed layers of cyclonic eddies and warmer temperature in the mixed layers of anticyclonic eddies. While we have insufficient observations at depth to fully identify the mechanism, we can hypothesize some likely causes. Cyclonic eddies tend to feature a prominent doming of near surface isopycnals, bringing the fresher and colder waters associated with the SML in closer proximity to the mixed layer (our observations, Chaigneau et al. [2011] and Colas et al. [2011]). Besides being closer to the mixed layer, these prominent cool and fresh anomalies could enhance double diffusive mixing and salt fingering in cyclonic eddies. Prior work has suggested that salt fingering may be an important mixing process in the SEP [e.g., Tsuchiya and Talley, 1998; Wong and Johnson, 2003; and Sato and Suga, 2009]. Salt fingering and double diffusion staircases occur when warm, salty water overlies cool, fresh water [Schmitt, 1994]; these conditions are common in the SEP, and can be intensified in cyclonic eddies due to the doming of near-surface isopycnals. Structures resembling thermohaline staircases were evident in eddy $\mathrm{C} 1$ during VOCALS-REx, both near the eddy center and edge (Figure 14). In anticyclonic eddies, doming of the SML and near-surface isopycnals can be less prominent [Colas et al., 2011] and occasionally depressed (eddies A1 and A2), perhaps isolating the mixed layer from the cold and fresh water at depth. This enhanced mixing mechanism is not limited to eddies. Any ocean feature that uplifts the SML and its associated temperature gradient could result in colder surface temperatures via vertical mixing.

[46] Argo salinity observations reinforce the hypothesis that the structure of cyclonic eddies could enhance vertical mixing. We calculated the mixed-layer salinity anomaly of Argo profiles within CH2011 eddies, just as we did in Section 5 for temperature. The mixed layers of anticyclonic eddies were more saline $(0.03 \pm .008 \mathrm{psu})$ than mean conditions and the mixed layers of cyclonic eddies were fresher $(-0.03 \pm .008 \mathrm{psu})$ than mean conditions. On average, the SML was $23 \pm 4 \mathrm{~m}$ deeper in anticyclonic eddies than in cyclonic eddies. The region between the base of the mixed layer and the SML was colder (by $0.2^{\circ} \mathrm{C} \pm 0.1^{\circ} \mathrm{C}$ ) and fresher (by $0.06 \pm 0.01 \mathrm{psu}$ ) in cyclonic eddies than in anticyclonic eddies. As precipitation provides minimal freshwater in the SEP [Colbo and Weller, 2007], the SML could be a primary source of freshwater to the mixed layer. The fresh mixed-layer salinity anomalies could therefore be interpreted as evidence of enhanced vertical mixing in cyclonic eddies.

[47] Our estimate of the average surface-layer eddy heat flux divergence of the SEP is small, indicating that eddies likely make a small contribution to the surface heat balance offshore in the SEP. The eddy heat flux divergence and the eddy SLA upper-ocean temperature analysis presented in section 5 suggest that eddies do not trap and coherently transport cool, coastal waters offshore in their surface layers. However, the magnitude of the eddy heat flux divergence is larger near the coast, particularly the large cooling flux near the coast of Peru, indicating that eddies could contribute to the heat balance in coastal regions, as suggested by Colas et al. [2011].
[48] In contrast to the heat budget calculated by Colbo and Weller [2007], which implied that eddies were important to the upper-ocean heat budget of the SEP, many recent studies, including this one, have found that eddies are likely not as important to the upper-ocean heat budget of the SEP as Colbo and Weller [2007] suggested. Colbo and Weller [2007] calculated the heat budget over the upper $250 \mathrm{~m}$, whereas our study focuses on observations of the eddies' mixed-layer temperatures, and so is difficult to directly compare to Colbo and Weller [2007]. Our analyses, using a wide variety of data sources, consistently suggest that eddies have a small surface temperature signal and likely make a small net contribution to the surface heat budget.

[49] What processes close the upper-ocean heat budget of the SEP, or why coupled GCMs show biases in the region, remain unresolved questions. de Szoeke et al. [2010] examined October data from 15 IPCC coupled GCMs, ship observations, and observation-based heat fluxes, and attributed the flux errors in the models to overestimates of solar radiation and evaporation at the surface. Cronin et al. [2006] also found too much solar radiation at the surface in various reanalysis products. Zheng et al. [2011] examined 19 coupled GCMs and found that biases in heat transport by Ekman currents largely contributed to the warm SST biases both near the coast and in the open ocean. In a modeling study, Shinoda and Lin [2009] found that meridional heat advection associated with ENSO events primarily controlled the interannual SST variation in the stratus cloud region north of $20^{\circ} \mathrm{S}$. Further work is needed to understand the upper-ocean heat budget of the SEP, as well as its complex relationship with the stratus deck.

[50] Acknowledgments. We thank the crew of the NOAA Ship, Ronald $\mathrm{H}$. Brown and all of the many colleagues who helped in collecting the UCTD and other hydrographic data during VOCALS-REx. Particular thanks also go to Sean Whelan, Jeff Lord and the entire Upper Ocean Process group at WHOI. We thank Jules Hummon and the Shipboard ADCP Data Acquisition Center at University of Hawaii for processing the underway ADCP data. We are also greatly indebted to Peter Gaube and Dudley Chelton (OSU) for providing us with near real-time sea-surface height and SST gridded fields which enabled us to locate the eddies during the cruise. The suggestions of three reviewers greatly improved the manuscript. This work was supported by NOAA's Climate Program Office and by NSF Grant OCE-0745508. Microwave OI SST data are produced by Remote Sensing Systems and sponsored by National Oceanographic Partnership Program (NOPP), the NASA Earth Science Physical Oceanography Program, and the NASA MEaSUREs DISCOVER Project. The altimeter SLA fields are produced by Ssalto/Duacs and distributed by AVISO with support from Centre National d'Etudes Spatiales. MDT_CNES-CLS09 was produced by CLS Space Oceanography Division and distributed by Aviso, with support from Cnes.

\section{References}

Beal, L. M., T. K. Chereskin, Y. D. Lenn, and S. Elipot (2006), The sources and mixing characteristics of the Agulhas current, J. Phys. Oceanogr. 36, 2060-2074, doi:10.1175/JPO2964.1.

Blanco, J. L., A. C. Thomas, M.-E. Carr, and P. T. Strub (2001), Seasonal climatology of hydrographic conditions in the upwelling region off northern Chile, J. Geophys. Res., 106, 11451-11468.

Boville, B. A., and P. R. Gent (1998), The NCAR climate system model, Version One, J. Clim., 11, 1115-1130.

Chaigneau, A., M. Le Texier, G. Eldin, C. Grados, and O. Pizarro (2011), Vertical structure of mesoscale eddies in the eastern South Pacific Ocean: A composite analysis from altimetry and Argo profiling floats, J. Geophys. Res., 116, C11025, doi:10.1029/2011JC007134.

Chaigneau, A., and O. Pizarro (2005a), Eddy characteristics in the eastern South Pacific, J. Geophys. Res. Oceans, 110, CO6005, doi: 10.1029/2004JC002815. 
Chaigneau, A., and O. Pizarro (2005b), Mean surface circulation and mesoscale turbulent flow characteristics in the eastern South Pacific from satellite tracked drifters, J. Geophys. Res. Oceans, 110, CO5014, doi: 10.1029/2004JC002628.

Chelton, D. B., R. A. De Szoeke, M. G. Schlax, K. El Naggar, and N. Siwertz (1998), Geographical variability of the first Baroclinic Rossby radius of deformation, J. Phys. Oceanogr., 28, 433-460.

Chelton, D. B., M. G. Schlax, and R. M. Samelson (2011), Global observations of nonlinear mesoscale eddies, Progr. Oceanogr., 91, 167-216.

Colas, F., J. McWilliams, X. Capet, and J. Kurian (2011), Heat balance and eddies in the Peru-Chile current system, Clim. Dynam., 39, 509-529.

Colbo, K., and R. Weller (2007), The variability and heat budget of the upper ocean under the Chile-Peru stratus, J. Mar. Res., 65, 607-637.

Cronin, M. F., N. A. Bond, C. W. Fairall, and R. A. Weller (2006), Surface cloud forcing in the East Pacific stratus Deck/Cold tongue/ITCZ complex, J. Clim., 19, 392-409.

de Szoeke, S. P., C. W. Fairall, D. E. Wolfe, L. Bariteau, and P. Zuidema (2010), Surface flux observations on the southeastern tropical Pacific Ocean and attribution of SST errors in coupled Ocean-Atmosphere models, J. Clim., 23, 4152-4174.

de Szoeke, S. P., and S.-P. Xie (2008), The tropical eastern pacific seasonal cycle: Assessment of errors and mechanisms in IPCC AR4 coupled ocean atmosphere general circulation models*, J. Clim., 21, 2573-2590.

Early, J. J., R. M. Samelson, and D. B. Chelton (2011), The evolution and propagation of quasigeostrophic ocean Eddies*, J. Phys. Oceanogr., 41, $1535-1555$.

Flierl, G. R. (1981), Particle motions in large-amplitude wave fields, Geophys. Astrophys. Fluid. Dynam., 18, 39-74, doi:10.1080/ 03091928108208773.

Gentemann, C. L., C. J. Donlon, A. Stuart-Menteth, and F. J. Wentz (2003), Diurnal signals in satellite sea surface temperature measurements, Geophys. Res. Lett., 30, 1140, doi:10.1029/2002GL016291.

Gordon, C. T., A. Rosati, and R. Gudgel (2000), Tropical sensitivity of a coupled model to specified ISCCP low clouds, J. Clim., 13, 2239-2260.

Hartmann, D. L., M. E. Ockert-Bell, and M. L. Michelsen (1992), The effect of cloud type on Earth's energy balance: Global analysis, J. Clim., 5 , 1281-1304.

Holte, J., and L. Talley (2009), A new algorithm for finding mixed layer depths with applications to argo data and subantarctic mode water formation, J. Atmos. Ocean. Tech., 26, 1920-1939.

Johnson, G. C., and K. E. McTaggart (2010), Equatorial Pacific $13^{\circ} \mathrm{C}$ water eddies in the eastern subtropical South Pacific Ocean, J. Phys. Oceanogr, 40, 226-236.

Karstensen, J. (2004), Formation of the South Pacific shallow salinity minimum: A southern ocean pathway to the tropical pacific, J. Phys Oceanogr., 34, 2398-2412.

King, B. A., E. Firing, and T. M. Joyce (2001), Shipboard observations during WOCE, in Ocean Circulation and Climate, edited by G. Siedler, J. Church, and J. Gould, pp. 99-112, Academic Press, San Diego, Calif.

Klein, S. A., and D. L. Hartmann (1993), The seasonal cycle of low stratiform clouds, J. Clim., 6, 1587-1606.

Kurian, J., F. Colas, X. Capet, J. C. McWilliams, and D. B. Chelton (2011), Eddy properties in the California current system, J. Geophys. Res. Oceans, 116, 8027, doi:10.1029/2010JC006895.

Large, W. G., and G. Danabasoglu (2006), Attribution and impacts of upperocean biases in CCSM3, J. Clim., 19, 2325-2346.

Lauer, A., K. Hamilton, Y. Wang, V. T. J. Phillips, and R. Bennartz (2010), The impact of global warming on marine boundary layer Clouds over the eastern pacific - A regional model study, J. Clim., 23, 5844-5863.

Lehahn, Y., F. d'Ovidio, M. Lévy, Y. Amitai, and E. Heifetz (2011), Long range transport of a quasi isolated chlorophyll patch by an Agulhas ring, Geophys. Res. Lett., 38, 16610, doi:10.1029/2011GL048588.

Leth, O., and J. F. Middleton (2004), A mechanism for enhanced upwelling off central Chile: Eddy advection, J. Geophys. Res. Oceans, 109, C12020, doi:10.1029/2003JC002129.
Leth, O., and G. Shaffer (2001), A numerical study of the seasonal variability in the circulation off central Chile, J. Geophys. Res., 106, 22229-22248

Lin, J.-L. (2007), The double-ITCZ problem in IPCC AR4 coupled GCMs: Ocean atmosphere feedback analysis, J. Clim., 20, 4497-4525

Ma, C.-C., C. R. Mechoso, A. W. Robertson, and A. Arakawa (1996), Peruvian stratus clouds and the tropical pacific circulation: A coupled ocean-atmosphere GCM study, J. Clim., 9, 1635-1645.

Mechoso, C.R., et al. (1995), The seasonal cycle over the tropical pacific in coupled ocean atmosphere general circulation models, Mon Weather Rev, 123, 2825-2838.

Niiler, P., A. Sybrandy, K. Bi, P. Poulain, and D. Bitterman (1995), Measurements of the water-following capability of holey-sock and TRISTAR drifters, Deep Sea Res. Oceanogr. Res. Paper, 42, 1951-1955

Norris, J. R., and C. B. Leovy (1994), Interannual variability in stratiform cloudiness and Sea surface temperature, J. Clim., 7, 1915-1925.

Reid, J. (1973), Transpacific hydrographic sections at Lats. $43^{\circ} \mathrm{S}$ and $28^{\circ} \mathrm{S}$ : The SCORPIO expedition-III. Upper water and a note on southward flow at mid-depth, Deep Sea. Res., 20, 39-49.

Ridgway, K. R., J. R. Dunn, and J. L. Wilkin (2002), Ocean interpolation by four-dimensional weighted least squares-Application to the waters around Australasia, J. Atmos. Ocean Tech., 19, 1357, doi:10.1175/15200426(2002)019<1357:OIBFDW>2.0.CO;2.

Sato, K., and T. Suga (2009), Structure and modification of the South Pacific Eastern subtropical mode water, J. Phys. Oceanogr., 39, 1700-1714, doi: 10.1175/2008JPO3940.1.

Schmitt, R. W. (1994), Double diffusion in oceanography, Annu. Rev. Fluid Mech., 26, 255-285.

Schneider, W. R Fuenzalida, E. Rodríguez-Rubio, J. Garcés-Vargas, and L. Bravo (2003), Characteristics and formation of Eastern South Pacific Intermediate Water, Geophys. Res. Lett., 30, 1581, doi: 10.1029/2003GL017086.

Shinoda, T., and J. Lin (2009), Interannual variability of the upper ocean in the Southeast Pacific Stratus Cloud Region, J. Clim., 22, 5072-5088.

Sparrow, M., O. Boebel, V. Zervakis, W. Zenk, A. Cantos-Figuerola, and W. J. Gould (2002), Two circulation regimes of the mediterranean outflow revealed by Lagrangian measurements, J. Phys. Oceanogr., 32, $1322-1330$.

Stammer, D. (1998), On Eddy characteristics, Eddy transports, and mean flow properties, J. Phys. Oceanogr, 28, 727-739.

Toniazzo, T., C. R. Mechoso, L. C. Shaffrey, and J. M. Slingo (2010), Upper-ocean heat budget and ocean eddy transport in the south-east Pacific in a high-resolution coupled model, Climate Dynamics, 35, 1309-1329.

Treguier, A., O. Boebel, B. Barnier, and G. Madec (2003), Agulhas eddy fluxes in a $1 / 6^{\circ}$ Atlantic model1, Deep Sea Research Part II: Topical Studies in Oceanography, 50, 251-280

Tsuchiya, M., and L. D. Talley (1998), A Pacific hydrographic section at $88^{\circ} \mathrm{W}$ : Water-property distribution, J. Geophys. Res., 1031 12899-12918, doi:10.1029/97JC03415.

Wentz, F. J., C. Gentemann, D. Smith, and D. Chelton (2000), Satellite measurements of sea surface temperature through clouds, Science, 288, $847-850$

Wong, A. P. S., and G. C. Johnson (2003), South pacific eastern subtropical mode water, J. Phys. Oceanogr., 33, 1493-1509, doi:10.1175/15200485(2003)033<1493:SPESMW>2.0.CO;2.

Wood, R., et al. (2011), The VAMOS ocean-cloud-atmosphere-land study regional experiment (VOCALS-REx): goals, platforms, and field operations, Atmos. Chem. Phys., 11, 627-654.

Wunsch, C. (1999), Where do ocean eddy heat fluxes matter? J. Geophys. Res., 104, 13235-13250, doi:10.1029/1999JC900062.

Zheng, Y., T. Shinoda, G. N. Kiladis, J. Lin, E. J. Metzger, H. E. Hurlburt and B. S. Giese (2010), Upper-ocean processes under the stratus cloud deck in the Southeast Pacific Ocean, J. Phys. Oceanogr., 40, 103-120.

Zheng, Y. T. Shinoda, J-L. Lin, and G. N. Kiladis (2011), Sea surface temperature biases under the stratus cloud deck in the Southeast Pacific Ocean in 19 IPCC AR4 coupled general circulation models, J. Clim., 24, 4139-4164. 